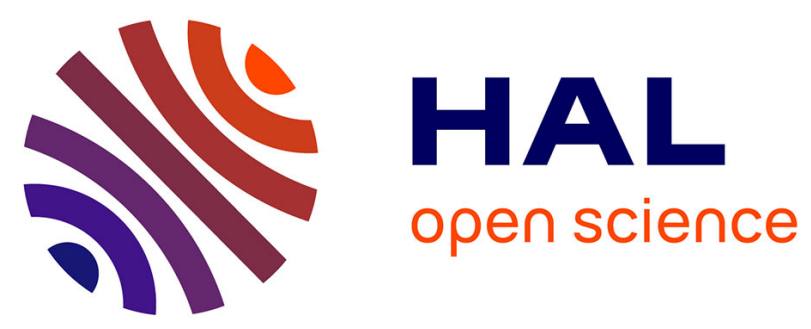

\title{
Assessment and potential of membrane cascades for organic solvent nanofiltration of hydroformylation media through a graphical representation composed of performance maps
}

A. Lejeune, M. Rabiller-Baudry, T. Renouard, B. Balannec, Y. Liu, J. Augello, D. Wolbert

\section{To cite this version:}

A. Lejeune, M. Rabiller-Baudry, T. Renouard, B. Balannec, Y. Liu, et al.. Assessment and potential of membrane cascades for organic solvent nanofiltration of hydroformylation media through a graphical representation composed of performance maps. Chemical Engineering Science, 2018, 183, pp.240-259. 10.1016/j.ces.2018.03.025 . hal-01774400

HAL Id: hal-01774400

https://hal-univ-rennes1.archives-ouvertes.fr/hal-01774400

Submitted on 25 May 2018

HAL is a multi-disciplinary open access archive for the deposit and dissemination of scientific research documents, whether they are published or not. The documents may come from teaching and research institutions in France or abroad, or from public or private research centers.
L'archive ouverte pluridisciplinaire HAL, est destinée au dépôt et à la diffusion de documents scientifiques de niveau recherche, publiés ou non, émanant des établissements d'enseignement et de recherche français ou étrangers, des laboratoires publics ou privés. 


\section{Accepted Manuscript}

Assessment and potential of membrane cascades for organic solvent nanofiltration of hydroformylation media through a graphical representation composed of performance maps

Antoine Lejeune, Murielle Rabiller-Baudry, Thierry Renouard, Béatrice Balannec, Yatong Liu, Jonathann Augello, Dominique Wolbert

PII: S0009-2509(18)30155-6

DOI: https://doi.org/10.1016/j.ces.2018.03.025

Reference: CES 14099

To appear in:

\section{Chemical Engineering Science}

Received Date: $\quad 28$ September 2017

Revised Date: $\quad 7$ March 2018

Accepted Date: $\quad 12$ March 2018

Please cite this article as: A. Lejeune, M. Rabiller-Baudry, T. Renouard, B. Balannec, Y. Liu, J. Augello, D. Wolbert, Assessment and potential of membrane cascades for organic solvent nanofiltration of hydroformylation media through a graphical representation composed of performance maps, Chemical Engineering Science (2018), doi: https://doi.org/10.1016/j.ces.2018.03.025

This is a PDF file of an unedited manuscript that has been accepted for publication. As a service to our customers we are providing this early version of the manuscript. The manuscript will undergo copyediting, typesetting, and review of the resulting proof before it is published in its final form. Please note that during the production process errors may be discovered which could affect the content, and all legal disclaimers that apply to the journal pertain. 


\title{
Assessment and potential of membrane cascades for organic solvent nanofiltration of hydroformylation media through a graphical representation composed of performance maps
}

\author{
Antoine Lejeune, Murielle Rabiller-Baudry*, Thierry Renouard, Béatrice Balannec, Yatong \\ Liu, Jonathann Augello, Dominique Wolbert \\ Univ Rennes, ENSCR, CNRS, ISCR (Institut des Sciences Chimiques de Rennes) - \\ UMR 6226, F-35000 Rennes, France \\ *corresponding author: murielle.rabiller-baudry@ univ-rennes1.fr
}

\begin{abstract}
This paper aims at proposing a graphical representation composed of several performance maps to help to answer to some current questions that can puzzle membrane end-users facing the arrangement of membranes in cascade in order to better master separation of complex media. Indeed, different compromises can be highlighted according to realistic goals for the separation such as quality and recovery yield of each fraction/component, energy consumption and required membrane area. This representation needed first the systematic simulations of cascades of pre-selected configurations. These last ones were chosen thanks to the target application field, namely the organic solvent nanofiltration of a final synthesis media of hydroformylation that is a homogeneous catalysed reaction. We voluntary assumed the $a$ priori limitation of the number of stages to 5, anticipating that more complex cascades will probably be too expensive (both operating and capital costs). The graphical representation by itself is based on sets of six 2D-maps. Each map highlights relationships selected in an appropriate way between two of the six selected criteria: extraction/recovery, retentate/permeate quality/purity, membrane filtering area and overall energy consumption. For sake of illustration, the separation of 2 components $\mathbf{C}$ and $\mathbf{A}$ was considered. C/A has been chosen in a 1/1000 molar ratio, where $\mathbf{C}$ corresponds to the less retained component of the catalytic system that must be recovered in the retentate and $\mathbf{A}$ corresponds to the less transmitted product to extract in the permeate. In realistic nanofiltration conditions achieved in toluene, the rejections were experimentally determined on the initial media to filter. $\mathbf{C}$ has a high rejection $(88 \%)$ whereas $\mathrm{A}$ has a low one $(30 \%)$. The simulations of cascades were established using these constant values for rejection and the experimental permeate flux. For sake of an illustration of the use of the graphical representation, a case study was finally discussed regarding a given target of recovery for the two desired components, namely at least $99 \%$ of $\mathbf{C}$ recovery and better than $70 \%$ of $\mathbf{A}$ extraction. A complementary multi-criteria analysis was added aiming at facilitating the decision-making.
\end{abstract}




\section{Keywords}

Membrane cascade design, simulation, graphical representation for compromise evidencing, organic solvent nanofiltration, organometallic catalysed reactions, hydroformylation

\section{Introduction}

Organic transformations catalysed by homogeneous organometallic complexes generally lead to mixtures containing several solutes in highly different proportions. According to the 12 principles of green chemistry, atom economy must be increased to simultaneously increase the overall productivity and ensure a greener production scheme [1]. Consequently, the unreacted substrate and species belonging to the catalytic system must be recycled to the next batch synthesis. Simultaneously, both target species and unwanted side-products have to be extracted aiming at their respective valorisation. Moreover, the mastery of the organic solvent consumption is also challenging. The processed volumes have to be minimised as far as possible because of the toxicity. And solvent recycling can contribute to this objective.

Regarding the complexity of the media at the end of the chemical reaction, the separation of components is generally difficult and energy consuming. Historically, the chemical industry mainly performs distillation to achieve the fractionation in individual components, including the solvent. But besides these advantages, weaknesses also exist among which is the high energy consumption. Moreover, the soluble catalysts can be destroyed during the heating step, preventing from its reuse.

Besides distillation, emerging membrane processes, such as organic solvent nanofiltration (OSN), appear promising to ensure a greener production in fine organic chemistry [2-10]. OSN is classically performed at room temperature and allows to obtain two fractions, the retentate and the permeate, both containing solvent. When components to separate have close sizes and physico-chemical properties, the fractionation of a complex mixture in its individual compounds is generally impossible. In general, a one-step membrane separation leads to two enriched fractions with respect to the composition of the feed fluid. Of course, the enrichment level of the retentate and the permeate depends on the rejection of each solutes. The rejection itself depends on several parameters. Among them are the membrane and the hydrodynamic conditions applied during the separation such as the pressure, the filtration mode (dead-end or cross-flow) etc. The overall solute concentration as well as the concentration of each solute have also an impact on the transfer mechanisms through the membrane.

OSN requires membrane materials that must be resistant towards organic solvent. Some of them, as toluene, are known to be particularly harsh to filter regarding this condition. Nowadays, OSN suffers from a lack of sufficiently selective membranes that can be moreover commercially available. To overcome this insufficient selectivity, membrane cascades can be used. The principle of a cascade is as follows: at least one of the two obtained fractions of a single OSN step can be retreated by a second membrane arranged in a special configuration towards the previous one and this can be repeated (see below) until the goal achievement [11- 
17]. For instance, the group of Livingston in UK succeeded to run continuous three-stage membrane cascades for solvent exchange (exchange of a solute from toluene to methanol with a Starmem 122 polyimide membrane [14]). The same authors reported also on the concentration of an active pharmaceutical ingredient (API) in a mixture of ethyl acetate and methanol [12]. According to the best of our knowledge, that was the first proof of experimental feasibility of organic solvent nanofiltration cascades.

Nevertheless, several designs are conceptually possible for a membrane cascade. It depends on the number of stages applied to either retreat the retentate or the permeate of the first stage and how fractions are recirculated between stages.

It is important to distinguish membrane cascades from the "classical" multistage processes that are quite frequent at industrial scale. These last ones consist in the retreatment of only the successive retentate fractions: the retentate of a stage becomes the feed of the following one and so on, as in desalination plants using reverse osmosis, for instance. At least it is only an arrangement of membranes to increase the membrane filtering area in an appropriate way allowing to increase the concentration of the final retentate. In such scheme, all collected permeates are not filtered again, but can finally be mixed (or not depending on their further use). Sometimes, the multistage arrangement of membranes is also used to simultaneously achieve concentration and demineralisation using a diafiltration mode. This scheme consists in the addition of water at several stages of the multistage process. The water is mixed with the stage feed and generally eliminated in the permeate of the same stage as it is currently achieved in dairy industry when desalting lactose by nanofiltration of permeate issued from ultrafiltration of whey. Finally, when dealing with retreatment of retentates from consecutive stages, the membrane arrangement can be considered as a cascade only when recycling of permeates can be operated between stages, whatever the recycling position.

Consecutive retreatment of permeates can also be achieved: the permeate of a stage becoming the feed of the next stage, such scheme corresponds always to a membrane cascade. This can be achieved for the purification of active pharmaceutical ingredients as shown by Peeva et al. [15]. Of course, one can also propose recycling of retentates between stages. This type of retreatment was also coupled with diafiltration by Kim et al. [18] who performed a two-stage membrane cascade to separate PEG-400 and PEG-2000 in acetonitrile and focused on the control of the cascade varying the recycled flow from the second stage towards the first one.

To increase the extraction of a target molecule in the permeate, recycling of the appropriate flows between stages can be used without any addition of solvent. Following this approach, Caus et al. [16] showed the efficiency enhancement of the NF separation of glucose and sucrose in water with cascades up to 4 stages.

Finally, recycling can be understood as a pseudo-diafiltration. The main difference is that the solvent injected in a stage is not pure as in a classical diafiltration. Consequently, recycling appears as the best strategy, especially when filtering toxic organic solvent. Nevertheless, recycling can be engaged according to several scheme.

There is no conceptual limitation to imagine more or less complex cascades and for instance, some authors focused on superstructure membrane cascades that were optimized to 
simultaneously determine the process structure (number of stages and location of the recycle streams) and operating variables according to specified separation goals [19]. Attempts to rationally design membrane cascades have been done thanks to several adaptations of the method of McCabe-Thiele, usually used for distillation [12, 13, 20, 21, 22]. However, the method was highlighted to be complex because of many parameters that have to be taken into account.

A systematic experimental validation of the design of membrane cascades with many schemes in recycling position is not really feasible at pilot scale as well as at lab scale. Thus determination of designs thanks to simulations appears as a more realistic approach to select the most promising design. Usually, playing on the number of stages in the cascade and the operating conditions such as the transmembrane pressure and the volume reduction ratio (VRR, ratio of the feed flowrate to the retentate flowrate) allows to propose different designs and the final one is selected with respect to a cost optimization [11, 23]. Simulations are usually performed for gas separation such as Gabrielli et al. [24] who focused on the optimization of cascades up to 6 stages in different configurations using Pareto's graphs allowing to show the reachable compromises between energy consumption and membrane area.

Of course the cascade design is closely related to the objective of the separation and must be studied case by case. For that, three aspects have to be considered:

(i) The determination of a realistic objective

(ii) The simulation itself: basis and robustness of the calculations

(iii) The final analysis of the feasibility of the proposal

We have been regularly confronted to the difficulty of convincing chemists of the OSN potentiality if they are not already involved in membrane separations. This is a real brake for a better penetration and OSN remains nowadays little known in the chemical industry. Aiming at its massive integration we are convinced that some help is needed specifically oriented towards non-specialists of membrane separation processes.

We thought that a selection of a limited number of appropriate figures easy to understand can make sense to reach this objective. That is why, in this paper we propose such selection, further called "graphical representation". The interest is mainly to highlight in a simple way what can be done with membrane cascades and what is not realistic. The selected figures permit to answer to current questions of chemists. Of course, the quality and robustness of the graphical representation depends strongly on that of the simulations achieved to build up the figures.

In this paper, the "graphical representation" has been specifically dedicated to the particular case of catalysed reactions achieved in the presence of an expensive homogeneous organometallic complex to recycle. Among particularities of such media, it can be underlined that solutes are in highly different proportions. Moreover, these solutes have generally intermediate rejections. This is a much more complex case than those where one of the solutes is fully retained or fully transmitted. 


\section{Simulation of membrane cascades}

In this part the details required for the simulations are given. Membrane cascades are multistage processes involving different stages arranged according to more or less sophisticated configurations. All cascades start from a feed stage corresponding to a one-stage process.

\subsection{Selected architecture of membrane cascades for OSN}

In "basic" configurations, membrane stages are connected "in series" (Figure 1). Starting from the feed stage one can add stages to simultaneously retreat the retentate and the permeate or only the permeate.

Three sections have to be distinguished in the cascade:

$\circ \quad$ the feed stage (stage " 0 ")

$\circ \quad$ the retentate retreatment section (also called multistage [11, 25] or stripping $[12,26]$ section in reference to distillation). Further added stages will be labelled positively, e.g. $+\mathrm{n}, \mathrm{n}$ increases when increasing the stage number starting from stage " 0 " [27].

$\circ \quad$ the permeate retreatment section (also called multipass [11, 25] or enriching $[12,26]$ section in reference to distillation). Further added stages will be labelled negatively, e.g. -m, m increases when increasing the stage number starting from stage " 0 ".

Generally, pumps are added between stages to ensure the appropriate cross-flow velocity and compensate the pressure drop along a given stage. 


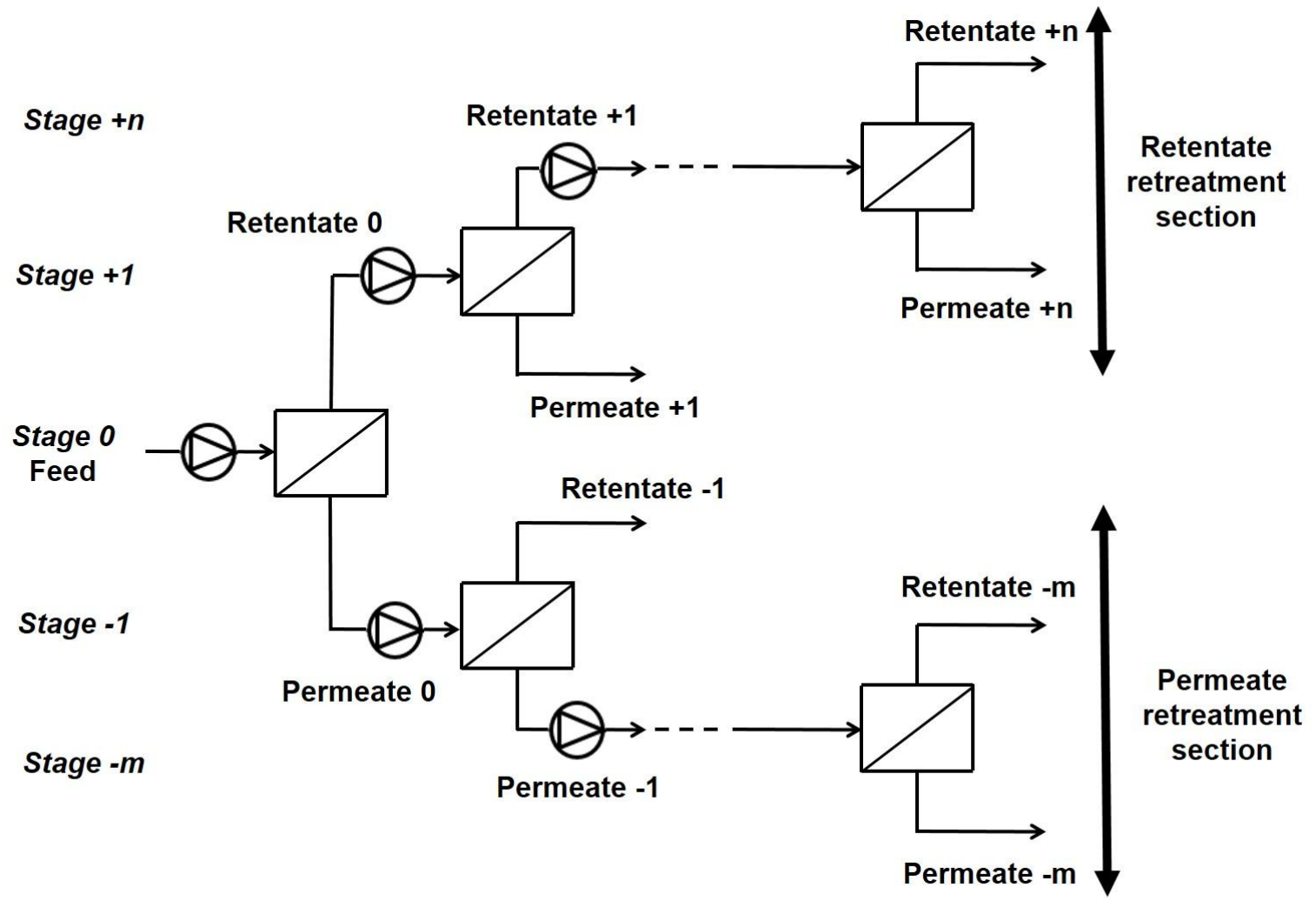

Figure 1: Basic membrane cascade with permeate and retentate retreatment sections.

(Opened triangle in circle corresponds to pumps)

In more sophisticated configurations, membrane stages remain connected "in series" but recyclings are added. The most common type of recycling is the return of "the loss fractions" from one stage back to the feed of the previous stage (Figure 2). According to this scheme, the permeate flows go back to the feed of the previous stage in the retentate retreatment section. On the contrary the retentate flows return to the feed of the previous stage in the permeate retreatment section. This design will be further referred to as "cascade with recycling" but is also called counter-current recycle cascade $[12,16,26]$. Pumps have to be added for all flows' recirculations. Moreover, mixers can be needed to homogenise mixed streams. This cascade configuration has only two outflows: one retentate collected on the final stage of the retentate retreatment section (stage " $+n$ ", where $n$ is the maximum value for the whole cascade) and one permeate collected on the final stage of the permeate retreatment section (stage "-m", where $m$ is the maximum value for the whole cascade). Other types of recyclings can be imagined: all recyclings towards the feed stage "0" [27], towards the opposite retreatment section [27] or towards several stages [23]. 


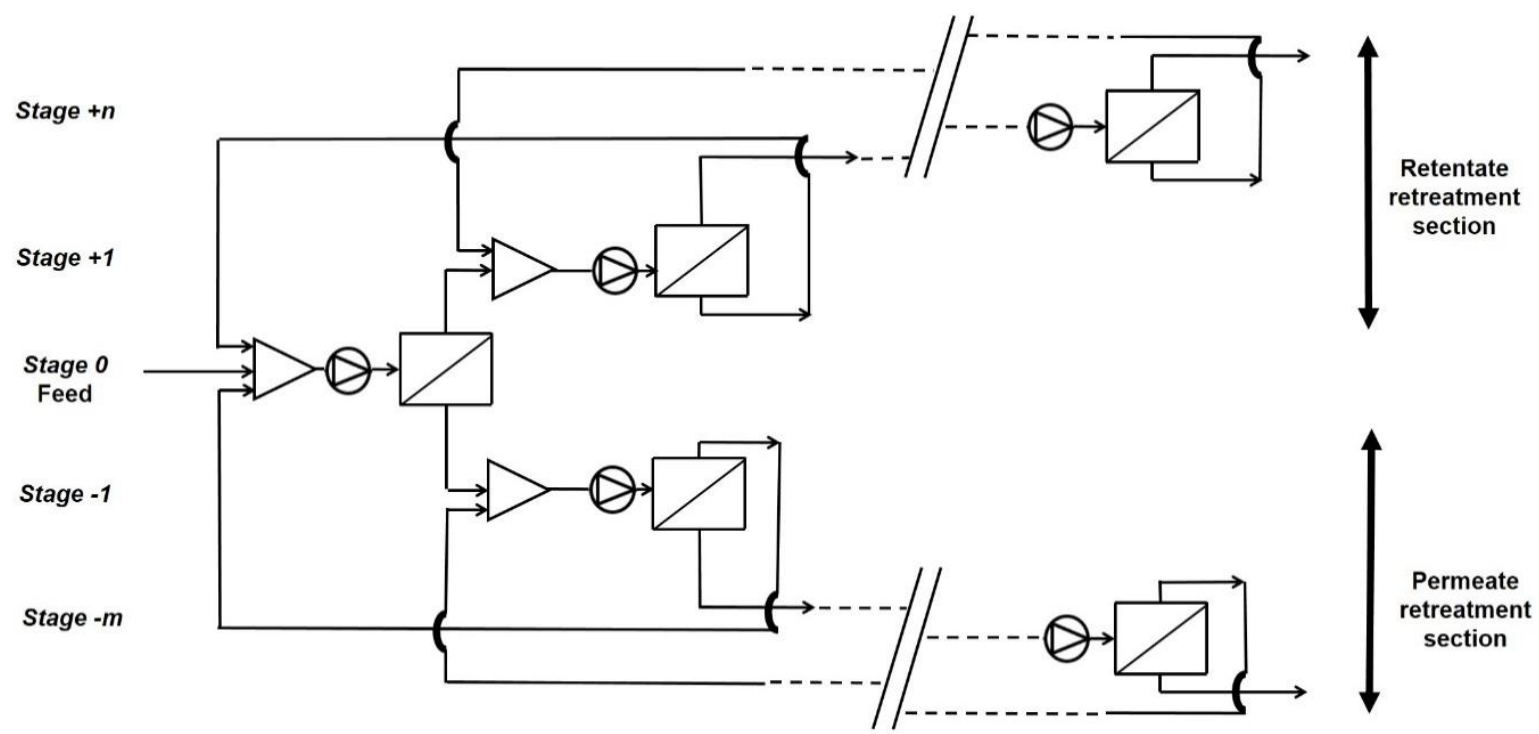

Figure 2: Membrane cascade with recycling from one stage to the previous one in permeate and retentate retreatment sections (opened triangles correspond to flow mixers and opened

triangle in circle to pumps). Note that stage " $+n$ " is the maximum value for the whole cascade in the retentate retreatment section and that stage "- $m$ " is the maximum value for the whole cascade in the permeate retreatment section.

Some authors considered that cascades with recycling from one stage towards the previous one (Figure 2) is the most energy efficient because mixing losses (and so the membrane area and pumping duty) are minimised [20]. But the generalisation of such affirmation is not so easy to do. Nevertheless, it seems that an important interest of such recycling mode is the relative simplicity to master the process at industrial level when compared to other recycling types. One can also notice that the comparison with usual distillation processes where a plate refers to a stage is possible for membrane cascades with recycling between 2 consecutive stages [21].

\subsection{Assumptions for simulation}

All simulations were performed using Microsoft Excel files. The assumptions to model the cascades were as follows:

○ continuous process ;

O steady-state process;

○ the feed of the membrane cascade is known (volumetric flowrates and concentrations);

$\circ$ the flows entering any stage have homogeneous concentrations suggesting perfect mixing with or without mixers ;

- a constant transmembrane pressure (TMP) of 10 bar is reached in a given stage ;

$\circ$ the temperature is constant over the whole process.

The permeate variables leaving a stage are considered average values obtained by integration as suggested in Figure 3. 


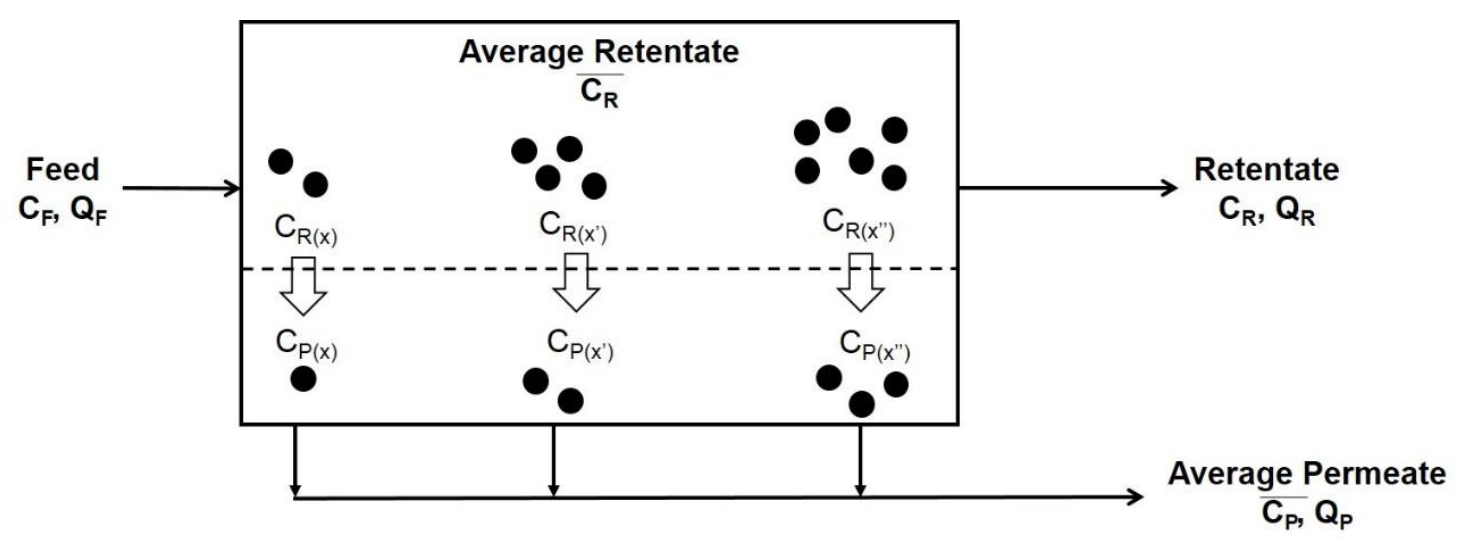

Figure 3: Outline of a membrane stage and definition of the average composition of the permeate leaving the stage. The indexes $F, R$ and $P$ refer to the feed, retentate and permeate, respectively.

The retentate that goes out of a stage is not an average value. It is calculated from the rejection which is fundamentally an experimental local value depending on operating conditions. The rejection $\operatorname{Ret}_{i}(X)$ of solute $X$ at stage $i$ is given by Eq. 1:

$\operatorname{Ret}_{\mathrm{i}}(\mathrm{X})=\left(1-\frac{\mathrm{C}_{\mathrm{P}, \mathrm{i}, \mathrm{t}}(\mathrm{X})}{\mathrm{C}_{\mathrm{R}, \mathrm{i}, \mathrm{t}}(\mathrm{X})}\right)$

With

$\mathrm{C}_{\mathrm{P}, \mathrm{i}, \mathrm{t}}(\mathrm{X})$ the permeate concentration of solute $\mathrm{X}$ at stage $\mathrm{i}$ and $\mathrm{t}$ time

$\mathrm{C}_{\mathrm{R}, \mathrm{i}, \mathrm{t}}(\mathrm{X})$ the retentate concentration of solute $\mathrm{X}$ at stage $\mathrm{i}$ and $\mathrm{t}$ time.

When considering a global stage, these local data have to be integrated as suggested in Figure 3.

\subsection{Mass balances for a single-stage process}

For a single-stage process labelled " 0 ", considering only one solute $\mathbf{X}, 4$ unknown variables (permeate and retentate flowrates and concentrations in both retentate and permeate) have to be determined. The feed flowrate $\mathrm{Q}_{\mathrm{F}, 0}$, the feed concentration $\mathrm{C}_{\mathrm{F}, 0}(\mathrm{X})$, the rejections and the VRR have been used for that purpose. The two outflows are obtained using the VRR definition (Eq. 28) and the following Eq. 2.

$\mathrm{Q}_{\mathrm{F}, 0}=\mathrm{Q}_{\mathrm{R}, 0}+\mathrm{Q}_{\mathrm{P}, 0}$

With

$\mathrm{Q}_{\mathrm{F}, 0}$ : the feed flowrate entering stage " 0 "

$\mathrm{Q}_{\mathrm{R}, 0}:$ the retentate flowrate 
$\mathrm{Q}_{\mathrm{P}, 0}:$ the permeate flowrate

Two other equations are necessary to determine the concentrations. The first one is the solute mass balance (Eq. 3):

$\mathrm{Q}_{\mathrm{F}, 0} \times \mathrm{C}_{\mathrm{F}, 0}(\mathrm{X})=\mathrm{Q}_{\mathrm{R}, 0} \times \mathrm{C}_{\mathrm{R}, 0}(\mathrm{X})+\mathrm{Q}_{\mathrm{P}, 0} \times \overline{\mathrm{C}_{\mathrm{P}, 0}}(\mathrm{X})$

With

$\mathrm{C}_{\mathrm{F}, 0}(\mathrm{X})$ : the concentration of solute $\mathrm{X}$ in the feed entering stage " 0 "

$\mathrm{C}_{\mathrm{R}, 0}(\mathrm{X})$ : the concentration at the stage retentate outlet (i.e. at VRR reached on this stage)

$\overline{\mathrm{C}_{\mathrm{P}, 0}}(\mathrm{X})$ : the average concentration of solute $\mathrm{X}$ in the permeate leaving the membrane module.

The last selected equation is the abatement reached at stage "i" dealing with solute $\mathbf{X}$ ( $\mathrm{Abt}_{\mathrm{i}}$ $(\mathrm{X})$ ). The abatement takes into account the rejection variation as well as the increase of concentration due to the VRR variation along the stage. It is a global performance data per stage expressed by Eq. 4 [28].

$\mathrm{Abt}_{\mathrm{i}}(\mathrm{X})=\left(1-\frac{\overline{\mathrm{C}_{\mathrm{P}, \mathrm{i}}(\mathrm{X})}}{\mathrm{C}_{\mathrm{F}, \mathrm{i}}(\mathrm{X})}\right)$

The average permeate concentration at stage " $\mathrm{i}$ " depends on both the rejection and the retentate concentration which vary with VRR over the stage. The general formula to calculate the average permeate concentration $\left(\overline{\mathrm{C}_{\mathrm{P}, \mathrm{i}}}(\mathrm{X})\right)$ is given by Eq. 5 .

$\overline{\mathrm{C}_{\mathrm{P}, \mathrm{i}}}(\mathrm{X})=\frac{1}{1-\frac{1}{\mathrm{VRR}}} \times \int_{0}^{1-\frac{1}{\mathrm{VRR}}}\left(1-\operatorname{Ret}_{\mathrm{i}}(\mathrm{X})\right) \times \mathrm{C}_{\mathrm{R}, \mathrm{i}}(\mathrm{X}) \times \mathrm{d}\left(1-\frac{1}{\mathrm{vrr}}\right)$

Experimental data supporting this study have shown that the solute concentration varied in a limited range in a given stage. Consequently, we assumed a constant rejection with VRR in a given stage. Thus, Eq. 5 turns into Eq. 6 (see Appendix 1 for calculation details) [28].

$\overline{\mathrm{C}_{\mathrm{P}, \mathrm{i}}}(\mathrm{X})=\frac{\mathrm{C}_{\mathrm{F}, \mathrm{i}}(\mathrm{X})}{1-\frac{1}{\mathrm{VRR}}} \times\left[1-\left(\frac{1}{\mathrm{VRR}}\right)^{\left(1-\operatorname{Ret}_{\mathrm{i}}(\mathrm{X})\right)}\right]$

Therefore, the abatement can be expressed with Eq. 7 in the case of a constant rejection.

$\operatorname{Abt}_{\mathrm{i}}(\mathrm{X})=1-\frac{1}{1-\frac{1}{\operatorname{VRR}}} \times\left[1-\left(\frac{1}{\operatorname{VRR}}\right)^{\left(1-\operatorname{Ret}_{\mathrm{i}}(\mathrm{X})\right)}\right]$

Contrary to traditional literature, we decided to implement the abatement in the solution method for computational reasons. Usually the fourth equation is that of the rejection which can be defined under various mathematical forms. 
In Eq. $1 C_{R}$ was the retentate concentration in $[\mathbf{1 2}, \mathbf{1 3}, \mathbf{1 5}]$. But it was substituted by the feed concentration in $[\mathbf{1 1}, \mathbf{1 6}, \mathbf{2 5}, \mathbf{2 9}, \mathbf{3 0}]$. These two values can be fairly different depending on the concentration reached at the stage outlet, or in other words depending on the stage VRR. But, regardless of the authors, $\mathrm{Cp}$ was always taken as the average concentration of the permeate, considering that perfect mixing was reached in the permeate (full) side of the filtration module.

For sake of understanding we have checked the numerical value of the permeate extraction (Eq. 22) according to the rejection calculated when using $C_{R}$ or $C_{F}$ in Eq. 1. We have also used the abatement calculated according to Eq. 7 for sake of comparison. The numerical case was that of a solute whose rejection was set constant at $30 \%$. Moreover an overall VRR equal to 10 was selected and it was assumed that this VRR was reached in a one-step process.

Figure 4 shows that the three calculated values were significantly different when considering a one-step calculation assuming that the membrane is a single element. Simulation according to the abatement led to $80 \%$ of extraction. This is an intermediate value between the two others for which the extractions were $86 \%$ and $63 \%$. The origin of differences is the consequence of the local character of the rejection that is not correctly taken into account when using an average data either that at the membrane inlet or that at the membrane outlet. Consequently, when using a single value of concentration, either the inlet $\left(\mathrm{C}_{\mathrm{F}}\right)$ or the outlet $\left(\mathrm{C}_{\mathrm{R}}\right)$ one, a numerical integration must be achieved to avoid significant errors.

To confirm this assessment calculations were achieved once again aiming at reproducing a step by step numerical integration. The membrane was divided in several parts (up to 15 elements corresponding to possible integration steps). For each selected integration step, all elements had the same area (depending on the number of steps). The sum of all area remained constant to always reach the desired VRR of 10. It was also assumed that the permeate was equally extracted from each element of a given selected integration step because the overall permeate flux has been assumed constant. When the number of membrane elements increased, calculations using rejection, regardless of the use of $C_{R}$ and $C_{F}$, tended towards the abatement and appeared strictly similar for 15 steps (Figure 4).

The following conclusion can thus be drawn. The calculation based on $C_{R}$ overestimates the permeate extraction whereas the one with $\mathrm{C}_{\mathrm{F}}$ underestimates it. On the contrary, the use of abatement led immediately to the convergence value. 


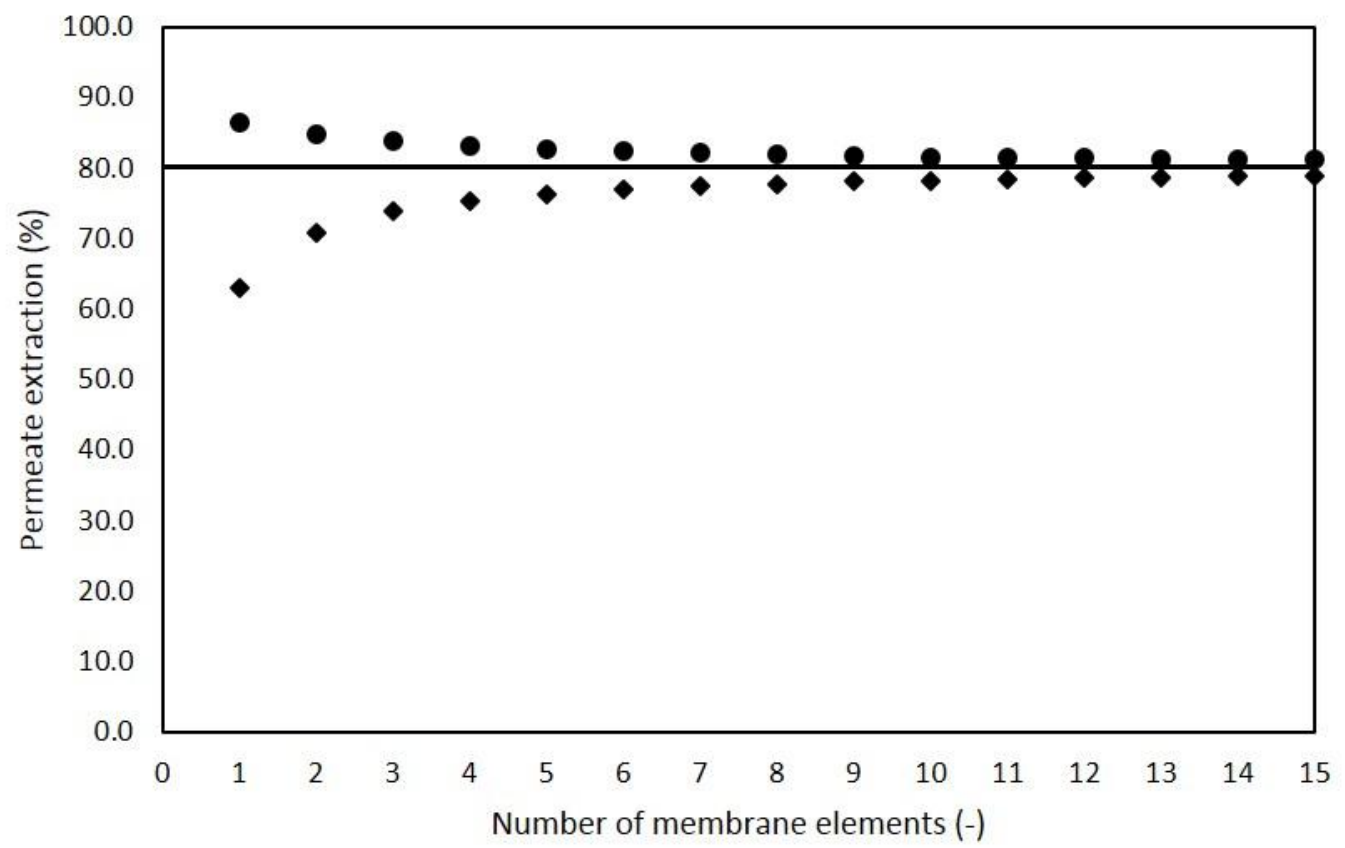

Figure 4: Comparison of the extraction of a solute (Eq. 22) whose rejection was $30 \%$ according to assumptions in the calculation method for a one-stage membrane process up to $V R R=10$. The number of membrane elements aims at modelling the numerical integration step. (full line: Abatement from $\boldsymbol{E q} .7-\bullet:$ Ret $=1-C_{P} / C_{F}$ (adapted from $\left.\boldsymbol{E q} . \mathbf{1}\right)-\bullet:$ Ret $=1$ -

$$
\left.C_{P} / C_{R}\right)(\boldsymbol{E q} .1)
$$

One can notice that Vanneste et al. [31] used an equation different from Eq. 7 for the abatement because they considered that there is an internal recycling of a part of the retentate towards the feed. However, in the present study, we considered that modules without internal recycling were used (corresponding to the case of classical spiral membrane in series or parallel, commonly used in reverse osmosis for instance [32]) that is why Eq. 7 is preferred.

\subsection{Mass balances for a membrane cascade with recycling (Figure 2)}

The modelling procedure for multistage processes with recycling was inspired from that of the single step process using abatement. For sake of clarity, a three-stage membrane cascade with recycling and with one stage in each retreatment section, design (+1 -1), is detailed to explain the used equations (Figure 5). 


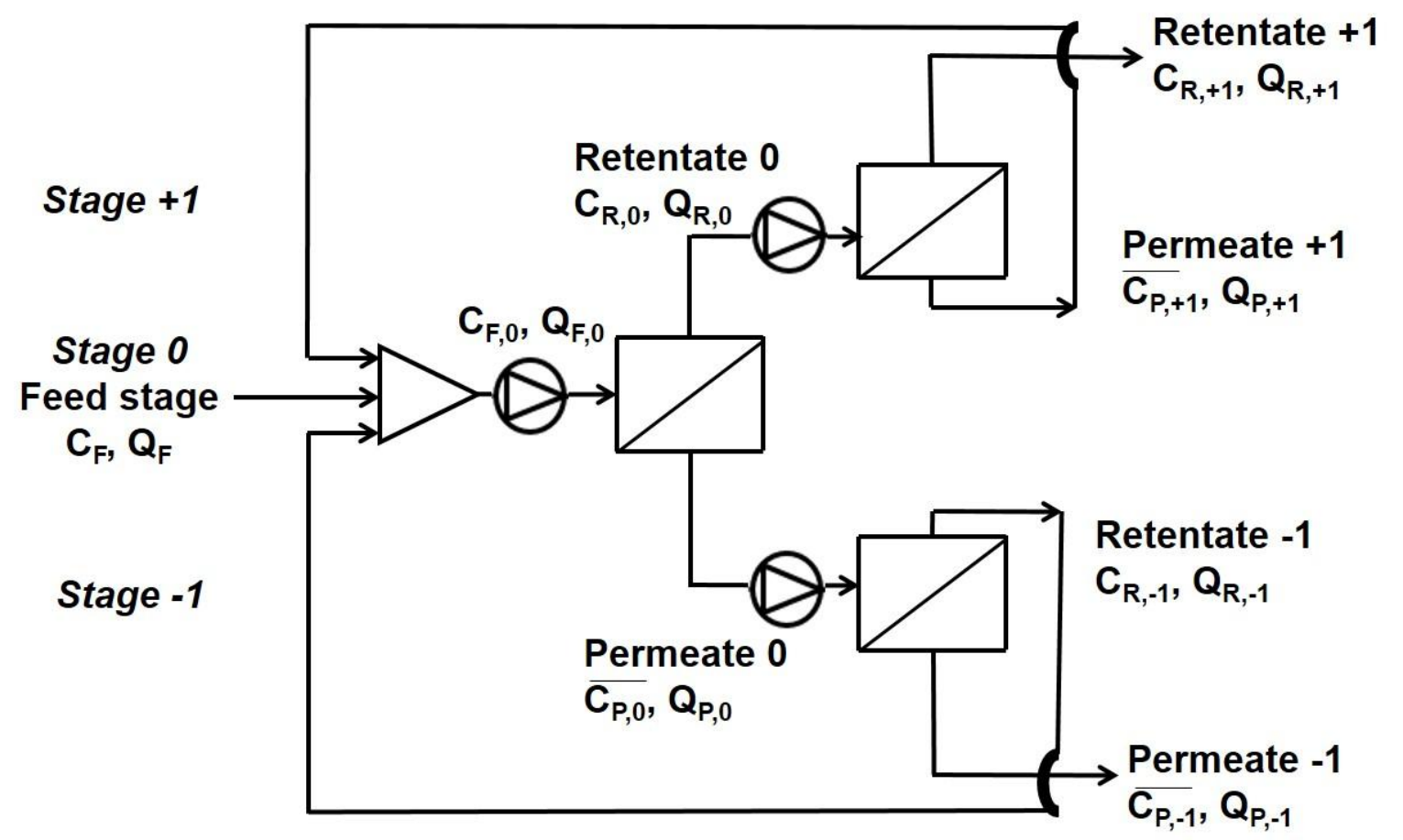

Figure 5: Three-stage membrane cascade with recycling (+1-1) (1 stage retentate retreatment section and 1 stage permeate retreatment section) - (opened triangle corresponds to flow mixer and opened triangle in circle to pumps)

For such cascade, 14 unknown variables had to be determined for one solute. At each stage, the same set of 4 equations as those used for the case for a one-stage process was used which generated 12 equations (Eq. 8 - 19). The last 2 needed equations were obtained at the mixer level of stage " 0 " (Eq. 20-21) [11, 25].

- Feed stage (stage 0):

$\mathrm{Q}_{\mathrm{F}, 0}=\mathrm{Q}_{\mathrm{R}, 0}+\mathrm{Q}_{\mathrm{P}, 0}$

$\mathrm{Q}_{\mathrm{F}, 0} \times \mathrm{C}_{\mathrm{F}, 0}=\mathrm{Q}_{\mathrm{R}, 0} \times \mathrm{C}_{\mathrm{R}, 0}+\mathrm{Q}_{\mathrm{P}, 0} \times \overline{\mathrm{C}_{\mathrm{P}, 0}}$

$\mathrm{VRR}_{0}=\frac{\mathrm{Q}_{\mathrm{F}, 0}}{\mathrm{Q}_{\mathrm{R}, 0}}$

Abatement $_{0}=1-\frac{\overline{\mathrm{C}_{\mathrm{P}, 0}}}{\mathrm{C}_{\mathrm{F}, 0}}=1-\frac{1}{1-\frac{1}{\mathrm{VRR}_{0}}} \times\left[1-\left(\frac{1}{\mathrm{VRR}_{0}}\right)^{(1-\mathrm{Ret})}\right]$

- Retentate retreatment section - Retentate side $($ stage +1$)$

$\mathrm{Q}_{\mathrm{F},+1}=\mathrm{Q}_{\mathrm{R},+1}+\mathrm{Q}_{\mathrm{P},+1}$

$\mathrm{Q}_{\mathrm{F},+1} \times \mathrm{C}_{\mathrm{F},+1}=\mathrm{Q}_{\mathrm{R},+1} \times \mathrm{C}_{\mathrm{R},+1}+\mathrm{Q}_{\mathrm{P},+1} \times \overline{\mathrm{C}_{\mathrm{P},+1}}$ 
(13)

$\mathrm{VRR}_{+1}=\frac{\mathrm{Q}_{\mathrm{F},+1}}{\mathrm{Q}_{\mathrm{R},+1}}$

Abatement $_{+1}=1-\frac{\overline{C_{P}+1}}{C_{F,+1}}=1-\frac{1}{1-\frac{1}{\mathrm{VRR}_{+1}}} \times\left[1-\left(\frac{1}{\mathrm{VRR}_{+1}}\right)^{(1-\mathrm{Ret})}\right]$

- Permeate retreatment section - Permeate side (stage -1)

$\mathrm{Q}_{\mathrm{F},-1}=\mathrm{Q}_{\mathrm{R},-1}+\mathrm{Q}_{\mathrm{P},-1}$

(16)

$\mathrm{Q}_{\mathrm{F},-1} \times \mathrm{C}_{\mathrm{F},-1}=\mathrm{Q}_{\mathrm{R},-1} \times \mathrm{C}_{\mathrm{R},-1}+\mathrm{Q}_{\mathrm{P},-1} \times \overline{\mathrm{C}_{\mathrm{P},-1}}$

$\mathrm{VRR}_{-1}=\frac{\mathrm{Q}_{\mathrm{F},-1}}{\mathrm{Q}_{\mathrm{R},-1}}$

Abatement $_{-1}=1-\frac{\overline{\mathrm{C}_{\mathrm{P}-1}}}{\mathrm{C}_{\mathrm{F},-1}}=1-\frac{1}{1-\frac{1}{\mathrm{VRR}_{-1}}} \times\left[1-\left(\frac{1}{\mathrm{VRR}_{-1}}\right)^{(1-\mathrm{Ret})}\right]$

- Feed stage mixing

$\mathrm{Q}_{\mathrm{F}, 0}=\mathrm{Q}_{\mathrm{R},-1}+\mathrm{Q}_{\mathrm{P},+1}+\mathrm{Q}_{\mathrm{F}}$

$\mathrm{Q}_{\mathrm{F}, 0} \times \mathrm{C}_{\mathrm{F}, 0}=\mathrm{Q}_{\mathrm{R},-1} \times \mathrm{C}_{\mathrm{R},-1}+\mathrm{Q}_{\mathrm{P},+1} \times \overline{\mathrm{C}_{\mathrm{P},+1}}+\mathrm{Q}_{\mathrm{F}} \times \mathrm{C}_{\mathrm{F}}$

\subsection{Limitation of the simulation range}

In the following, we considered that cascades with more than 5 stages are probably too expensive and consequently not realistic. Nevertheless, up to 7 stages have been sometimes simulated for sake of clarity (Table 1).

Table 1: Simulated membrane cascades and associated nomenclature for the cascade ${ }^{l}$. + : simulation without recycling ${ }^{2}$ (Figure 1), x: simulation with recycling (Figure 2).

\begin{tabular}{|c|c|c|c|c|c|}
\hline & \multicolumn{5}{|c|}{ Retentate retreatment section } \\
\hline & Stage 0 & Stage +1 & Stage +2 & Stage +3 & Stage +4 \\
\hline Stage 0 & (0) & $\begin{array}{c}+, \mathrm{x} \\
(+10)\end{array}$ & $\begin{array}{c}+, \mathrm{x} \\
(+20)\end{array}$ & $\begin{array}{c}+, \mathrm{x} \\
(+30)\end{array}$ & $\begin{array}{c}\mathrm{x} \\
(+40)\end{array}$ \\
\hline Stage -1 & $\begin{array}{c}+, x \\
(0-1)\end{array}$ & $\begin{array}{c}\mathrm{x} \\
(+1-1)\end{array}$ & $\begin{array}{c}\mathrm{x} \\
(+2-1)\end{array}$ & $\begin{array}{c}\mathrm{x} \\
(+3-1)\end{array}$ & \\
\hline
\end{tabular}




\begin{tabular}{|c|c|c|c|c|c|c|}
$\begin{array}{c}\text { Permeate } \\
\text { retreatment } \\
\text { section }\end{array}$ & Stage -2 & $\begin{array}{c}+, \mathrm{x} \\
(0-2)\end{array}$ & $\begin{array}{c}\mathrm{x} \\
(+1-2)\end{array}$ & $\begin{array}{c}\mathrm{x} \\
(+2-2)\end{array}$ & & \\
\cline { 2 - 7 } & Stage -3 & $\begin{array}{c}+, \mathrm{x} \\
(0-3)\end{array}$ & $\begin{array}{c}\mathrm{x} \\
(+1-3)\end{array}$ & & $\begin{array}{c}\mathrm{x} \\
(+3-3)\end{array}$ & \\
\cline { 2 - 7 } & Stage -4 & $\begin{array}{c}\mathrm{x} \\
(0-4)\end{array}$ & & & & \\
\hline
\end{tabular}

${ }^{I}$ The cascades will further be named by the label of their final stages (labelled positively for the retentate and negatively for the permeate). For instance, a 5-stage membrane cascade with 2 stages in each section will be named (+2 -2); a 4-stage membrane cascade with 2 stages in the retentate retreatment section and 1 in the permeate retreatment section will be named $(+2-1)$ and a 3-stage membrane cascade with only a retentate retreatment section will be called $(+20)$ (see also ref. [27]).

2 according to remark already written, when the membrane arrangement only concerns consecutive retentate retreatments $(+n, 0)$ and in absence of recycling, simulations are not exactly that of cascades. But for sake of simplicity in Figure captions all simulations are referred to in short with the same nomenclature as that of "cascades"

\subsection{Criteria highlighting membrane cascade performances}

The objectives of a separation can be multiple. The representation interest is in the highlighting of compromises that have to be rapidly identified. Let's consider a $(+n-m)$ cascade configuration and the parameters required to appreciate its performances.

- The overall extraction of the product $\mathbf{A}$ (stage $-\mathrm{m})$ was defined by Eq. 22:

Permeate extraction of product $A=\frac{\overline{C_{P,-m}(A)} \times Q_{P,-m}}{C_{F}(A) \times Q_{F}}$

With:

$\overline{\mathrm{C}_{\mathrm{P},-\mathrm{m}}(\mathrm{A})}$ and $\mathrm{C}_{\mathrm{F}}(\mathrm{A})$ : the average concentration of product $\mathrm{A}$ in the final permeate (stage $-\mathrm{m}$ ) and its cascade feed concentration, respectively.

$\mathrm{Q}_{\mathrm{P},-\mathrm{m}}$ and $\mathrm{Q}_{\mathrm{F}}$ : the flowrates of the final permeate (stage $-\mathrm{m}$ ) and the feed, respectively.

- The overall recovery of catalyst $\mathbf{C}$ in the retentate (stage $+n$ ) was defined by Eq. 23:

Retentate recovery of catalyst $C=\frac{C_{R,+n}(C) \times Q_{R,+n}}{C_{F}(C) \times Q_{F}}$

With:

$\mathrm{C}_{\mathrm{R},+\mathrm{n}}(\mathrm{C})$ and $\mathrm{C}_{\mathrm{F}}(\mathrm{C})$ : the concentration of catalyst $\mathrm{C}$ in the final retentate (stage $+\mathrm{n}$ ) and in the cascade feed concentration, respectively.

$\mathrm{Q}_{\mathrm{R},+\mathrm{n}}$ : the flowrate of the final retentate $($ stage $+\mathrm{n})$. 
- The product A purity in the permeate (stage -m) was defined by Eq. 24:

Permeate purity of product $A=\frac{\overline{C_{P,-m}(A)} \times Q_{P,-m}}{\overline{C_{P,-m}(A)} \times Q_{P,-m}+\overline{C_{P,-m}(C)} \times Q_{P,-m}}$

(24)

With:

$\overline{\mathrm{C}_{\mathrm{P},-\mathrm{m}}(\mathrm{C})}$ the average concentration of catalyst $\mathrm{C}$ in the final permeate (stage $-\mathrm{m}$ ).

- The catalyst $\mathbf{C}$ retentate enrichment was defined by Eq. 25 :

It is another way to deal with purity but the enrichment is more adapted here because the catalyst $\mathbf{C}$ is much less concentrated than the product A. Consequently its purity will be always very low.

Retentate enrichment of catalyst $C=\frac{C_{R,+n}(C) \times Q_{R,+n} /\left(C_{R,+n}(C) \times Q_{R,+n}+C_{R,+n}(A) \times Q_{R,+n}\right)}{C_{F}(C) \times Q_{F} /\left(C_{F}(C) \times Q_{F}+C_{F}(A) \times Q_{F}\right)}$

With

$\mathrm{C}_{\mathrm{R},+\mathrm{n}}(\mathrm{A}):$ the concentration of product $\mathbf{A}$ in the final retentate (stage $+\mathrm{n}$ )

- The overall membrane area is the sum of the membrane area at each stage and was calculated with Eq. 26:

$A_{m b, i}=\frac{Q_{P, i}}{J_{i}}$

With

$A_{m b, i}:$ the membrane area at stage $\mathrm{i}$

$\mathrm{Q}_{\mathrm{P}, \mathrm{i}}$ : the permeate flowrate at stage $\mathrm{i}$

$\mathrm{J}_{\mathrm{i}}$ : the permeate flux at stage $\mathrm{i}$ which was calculated according to the formula in Table 2.

Table 2: Media on which the separation was achieved and assumption on fluxes and rejections in agreement with experimental results at TMP=10 bar of [27].

$\overline{C_{R}(A)}$ is the average retentate concentration of $\boldsymbol{A}$ experimentally showed to master the flux.

\begin{tabular}{lcc}
\hline & A & C \\
\hline $\begin{array}{l}\text { Concentration in feed } \\
\text { stream (mol.L } \text { - }^{-1}\end{array}$ & 1 & $10^{-3}$ \\
$\begin{array}{l}\text { Rejection at TMP=10 bar } \\
(\%)\end{array}$ & 30 & 88
\end{tabular}


- The energy consumption $\left(\mathrm{kWh} \cdot \mathrm{m}^{-3}\right)$ was calculated for each stream where a pump was necessary (Figures 2 and 3) with Eq. 27:

$\mathrm{W}_{\mathrm{OSN}, \mathrm{i}}=\left(\frac{\mathrm{TMP} \times \mathrm{Q}_{\mathrm{F}, \mathrm{i}}}{\eta_{\mathrm{pump}}}\right) \times \frac{1}{\mathrm{Q}_{\mathrm{F}}}$

With

$\eta_{\text {pump }}$ : the pump efficiency, chosen equal to 0.7 in good agreement with literature data [31].

TMP: the transmembrane pressure (chosen constant for all stages)

The energy needed for mixing (if any) was neglected.

- The Volume Reduction Ratio $\left(\mathrm{VRR}_{\mathrm{i}}\right)$ at a given stage $\mathrm{i}$ was defined by

$\operatorname{VRR}_{\mathrm{i}}=\frac{\mathrm{Q}_{\mathrm{F}, \mathrm{i}}}{\mathrm{Q}_{\mathrm{R}, \mathrm{i}}}$

With

$Q_{F, i}$ the feed flowrate and $Q_{R, i}$ the retentate flowrate at stage $i$, respectively.

For sake of simplicity, the same VRR was imposed at each stage of the cascades and chosen equal to 5, 8 and 10 for the simulations. Such values were selected with respect to values commonly used at industrial scale. The limitation of VRR is generally imposed by the viscosity increase. But for our target applications, the liquid pure products have generally a viscosity close to that of the pure organic solvent. More probably, the VRR limitation would be due to the dead yolume of the industrial equipment.

- The Volume Reduction Ratio of the overall cascade was defined according to Eq. 29:

overall cascade $\mathrm{VRR}=\frac{\mathrm{Q}_{\mathrm{F}}}{\mathrm{Q}_{\mathrm{R}, \mathrm{n}}}$

The VRR of the overall cascade deals with the technical feasibility of the cascade at industrial level. A too high value may be unrealistic because of the dead volume of the set-up. The maximum realistic value was not fixed at start but this parameter will be discussed in the following.

\section{Graphical representation to highlight the main compromises to solve}

This paper only aims at considering a separation entirely achieved by membrane processes. 
Of course, depending on the results it can be sometimes more realistic to combine membranes with other separation processes, but this aspect is out of the scope of the present study.

The approach detailed in this paper is devoted to the separation of mixtures issued from homogeneous organometallic catalysed reactions. More or less, all of such media are characterised by a low concentration in components of the catalytic system and a high concentration of the products of the reaction. Generally the catalyst $(\mathbf{C})$ to $\operatorname{product}(\mathrm{s})(\mathbf{A})$ molar ratio is in the range $\mathbf{C} / \mathbf{A}=1 / 1000$ to $1 / 100$.

The objective is to extract the product in the permeate and to concentrate the catalyst in the retentate. The recycling of the last one in the synthesis reactor could improve the overall process efficiency.

\subsection{Details on the selected media}

The selected media on which the separation must be achieved is detailed in Table 2 (in good agreement with experimental data obtained for OSN of an olefin hydroformylation media detailed in [27]). In short, the media to be filtered corresponds to that of the hydroformylation of 10-undecenitrile in toluene using a $\mathrm{Rh}(\mathrm{acac})(\mathrm{CO})_{2}$ catalyst precursor and biphephos as associated ligand. The membrane was a PDMS one.

The OSN objective was to extract the product $\mathbf{A}$ in the permeate and to recover the catalyst $\mathbf{C}$ in the retentate so that it can be recycled back to the synthesis reactor. All simulated nanofiltrations were performed at $\mathrm{TMP}=10 \mathrm{bar}$.

A represents the products of hydroformylation (assuming $100 \%$ conversion of substrate at 1 mol. $\mathrm{L}^{-1}$ initially). The overall concentration of the reaction products mastered the flux and so the value for $\mathbf{A}$ was chosen equal to $1 \mathrm{~mol} . \mathrm{L}^{-1}$. The rejection was different for all components when increasing the VRR. In simulations, A rejection was chosen as the initial rejection (30\% of rejection) of the less transmitted product to be extracted in the permeate which was also the target product of the reaction (linear aldehyde). This value was the less favourable for the cascade design.

C represents the overall catalytic system ( $\mathrm{Rh}$ precursor and biphephos ligand in 1/20 molar ratio). The main component of the catalytic system was the biphephos ligand initially at $10^{-3}$ mol. $\mathrm{L}^{-1}$. The rejection of the $\mathrm{Rh}$ catalyst was greater than that of the biphephos ligand. $\mathbf{C}$ rejection was chosen as the initial rejection of the less retained component of the catalytic system to be recovered in the retentate ( $88 \%$ of rejection) which was also the biphephos ligand. This value was the less favourable for the cascade design.

The overall amount of $\mathbf{A}$ to treat was set at 10,000 tons per year which corresponds to a medium scale production. The feed flow was $\mathrm{Q}_{\mathrm{F}}=6,400 \mathrm{~L} \cdot \mathrm{h}^{-1}$ for a $1 \mathrm{~mol} \cdot \mathrm{L}^{-1}$ feed solution (with about 20/80 v/v for liquid product $\mathbf{A} /$ solvent) and when considering continuous production achieved in $8,000 \mathrm{~h}$ during 333 days per year.

\subsection{Justification of selected relationships for the graphical representation conception}


The graphical representation by itself is based on a set of 2D-maps (abacuses). Each map shows relationships carefully selected to highlight important compromises to solve. The main selected criteria are the extraction/recovery of both $\mathbf{A}$ and $\mathbf{C}$, the retentate/permeate quality/purity/enrichment in both $\mathbf{C}$ and $\mathbf{A}$. But also the overall membrane filtering area and the global energy consumption are used.

Because rejections depend at least on membrane, transmembrane pressure and hydrodynamic conditions, it is not possible to generalise the results of simulations obtained for a given case (Table 2). Moreover, as the rejections depend also on the concentration, relationships between two selected criteria depend on the VRR at each stage. There is no conceptual limitation of the combination of VRR values at each stage. For sake of simplification, the same VRR has been selected for all stages of a given cascade.

Each map indicates the performances of all simulated configurations according to the two selected criteria.

- Map 1: permeate extraction of product $\mathbf{A}$ versus retentate recovery of catalyst $\mathbf{C}$

- Map 2: permeate extraction of product $\mathbf{A}$ versus membrane area

- Map 3: retentate recovery of catalyst $\mathbf{C}$ versus membrane area

- Map 4: permeate purity of product $\mathbf{A}$ versus membrane area

- Map 5: retentate enrichment of catalyst $\mathbf{C}$ versus membrane area

- Map 6: energy consumption versus overall membrane area

Map 1 deals with the compromise to accept between the two main goals of the separation process, namely the overall recovery of each solute in its respective enriched fraction. This abacus allows drawing the first conclusion about the most important result of the simulation: the feasibility of the components' recovery with respect to only scientific considerations.

Map 2 and Map 3 immediately highlight the second compromise to find with an important point of the economic viability of the separation by relating the extraction of the product $\mathbf{A}$ (the target of the synthesis) or the recovery of the catalyst $\mathbf{C}$ (to recycle in synthesis) to the membrane filtering area concerning both capital costs (CAPEX) and operating costs (OPEX).

Map 4 and Map 5 underline the quality of the two obtained fractions. By combination with Map 2 and Map 3, the compromise between recovery and quality can be found.

Map 6 deals with the energy consumption when only considering that due to the pressure drop over a stage and consequently the cost to re-increase it. This point is of course also related to OPEX.

Finally, the set of six maps established for a given VRR is only a part of the global graphical representation that must take into account all sets of six maps obtained for all realistic VRRs. For instance, the combination of Figure 6 and Figure 8-12 is the part of the global graphical representation devoted to $\mathrm{VRR}=5$. Whereas the parts devoted to $\mathrm{VRR}=8$ and $\mathrm{VRR}=10$ are different. They are given in Figures A-2 and A-3 in Appendix 2. 


\subsection{Meaning of 2D-maps constituting the graphical representation}

Whatever the two criteria putted in relation, all maps were similarly built-up. For sake of illustration, the part of the graphical representation established for VRR $=5$ at each stage of the cascade is shown Figure 6 and Figures 8-12.

Figure $\mathbf{6}$ shows the simulated permeate extraction of $\mathbf{A}$ and retentate recovery of $\mathbf{C}$ thanks to all tested cascade designs of Table 1 at VRR=5. Each dot represents one cascade design.

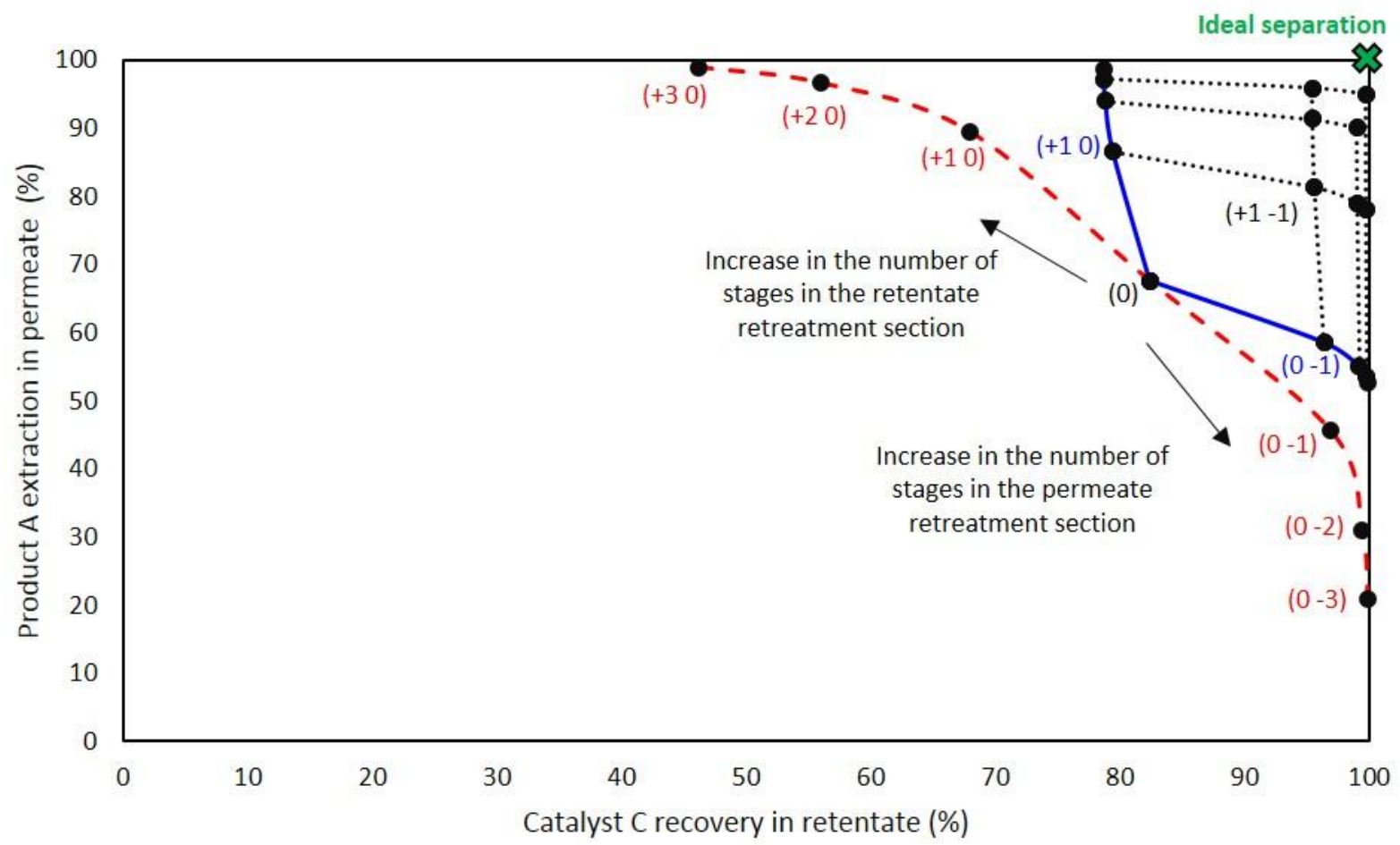

Figure 6: Results of the simulation of membrane cascades (Map 1 with VRR=5 at each stage): permeate extraction of product $\boldsymbol{A}$ in function of retentate recovery of catalyst $\boldsymbol{C}$. dashed lines: configurations without recycling - full lines: cascades with recycling with only a permeate or a retentate retreatment section - dotted lines: cascades with recycling with both permeate and retentate retreatment sections.

Map 1 is divided in two main zones limited by the dashed line including the one-stage process (dot "0"). The reachable performances are only in the upper right side of the map where the ideal separation has been indicated (green cross). All dots can be related thanks to a set of lines constituting a logical meshing.

The configurations without any recycling are on the red dashed lines. The upper side corresponds to only consecutive retreatments of retentate, labelled $(+n 0)$ (not really a cascade as already mentioned). The lower side corresponds to only consecutive retreatments of permeate, labelled $(0-\mathrm{m})$. Increasing the number of stages in the retentate retreatment section (positive labels) allows to increase the extraction of $\mathbf{A}$ in the permeate but systematically decreases the recovery of $\mathbf{C}$ in the retentate. An opposite trend is observed for the permeate 
retreatment section (negative labels).

The configurations with only a retentate retreatment section (respectively permeate retreatment section) with recycling from one stage to the previous one are on the blue full lines. These cascades remain far from the objective of the ideal separation but closer than the previous configurations on the red dashed lines. As expected, addition of recycling has a positive effect on the yield of recovery.

All configurations out of both the dashed lines and the full lines correspond to cascades with simultaneously a retentate and a permeate retreatment section, moreover with recycling in the two sections. All of them permit to get closer to the "ideal separation".

All the dots can be finally joined to create a logical meshing (dotted lines). Starting from the two branches of the blue full lines, the positively labelled one and the negatively labelled one allows identifying the cascade configuration at intersection when following the dotted lines. For instance in Figure 6, starting from design $(+10)$, adding one stage in the permeate retreatment section leads to design $(+1-1)$. The same design is of course reached by adding one stage in the retentate retreatment section at the design $(0-1)$.

As explained above, the choice of the VRR at each stage is crucial for the separation performances. The influence of the VRR is shown in Figure 7. For sake of simplicity, the dashed lines corresponding to configurations without any recycling are not indicated as these configurations are always the worse ones as already explained. Only the full lines dealing with either permeate or retentate retreatment sections with recycling are reported; they highlight the lowest performances reachable with cascades with recycling. The higher the VRR at each stage, the higher the product A permeate extraction but simultaneously the lower the catalyst $\mathbf{C}$ retentate recovery. Between $\mathrm{VRR}=5$ and $\mathrm{VRR}=10$ at each stage, a common zone leading to the "ideal separation" is accessible meaning that different choices in VRR can a priori be made to reach the same separation goal. 


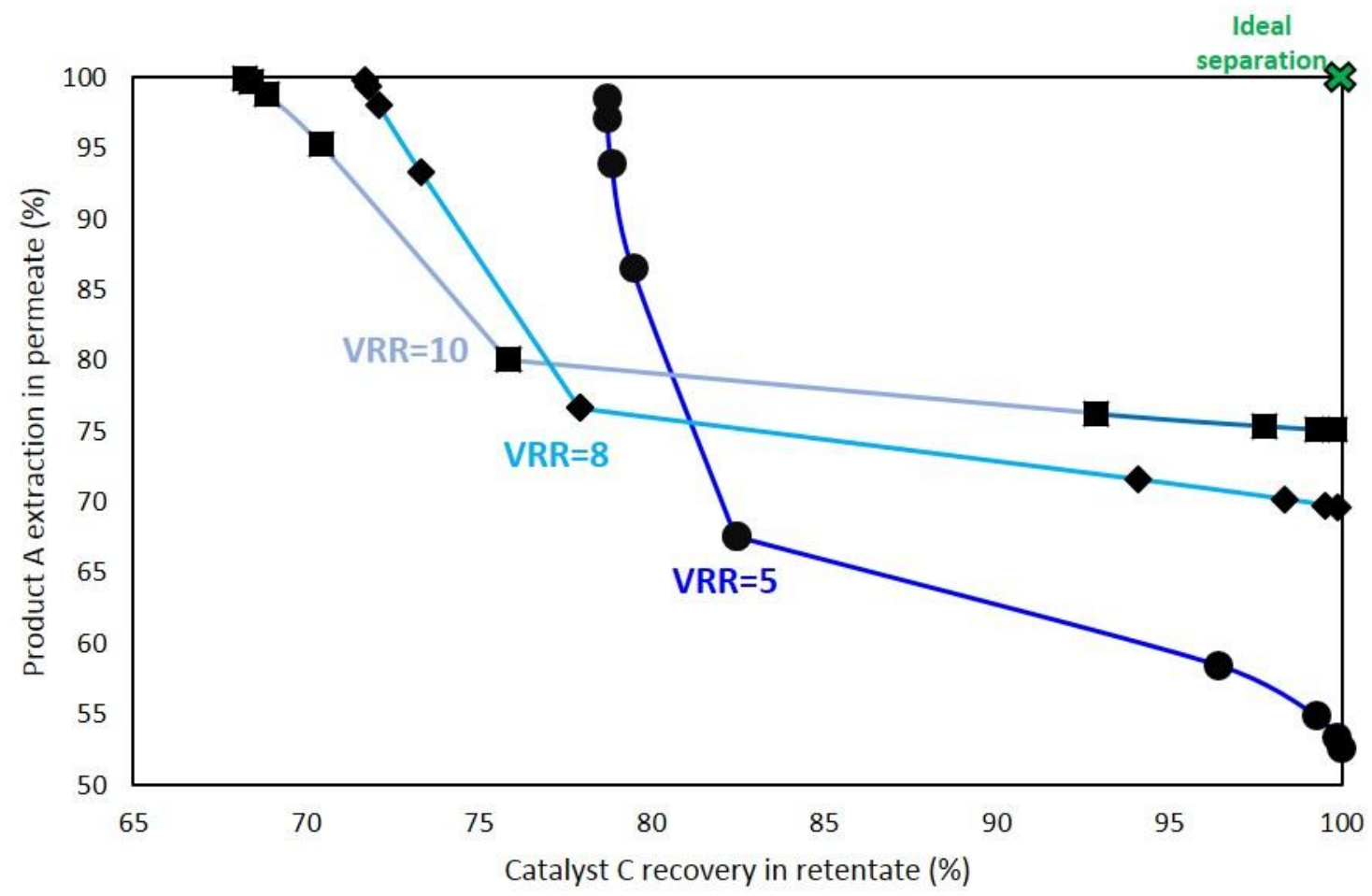

Figure 7: Influence of the VRR at each stage on the lowest performances reachable for membrane cascades with recycling with only a permeate or a retentate retreatment section (dots: VRR=5 - diamonds: VRR=8-squares: VRR=10)

Following the same general build-up as that shown on Figure 6, the extraction of $\mathbf{A}$ in the permeate (Figure 8), the recovery of $\mathbf{C}$ in the retentate (Figure 9), the purity of $\mathbf{A}$ in the permeate (Figure 10) and the enrichment of $\mathbf{C}$ in the retentate (Figure 11), were plotted versus the membrane area. As in Figure 6, two curves defined the lowest reachable performances with membrane cascades, either without or with recycling.

For all the four selected criteria, systematically the membrane area increases with the number of stages in the cascades. The lower area is shown by a vertical line corresponding to a onestage process on all these figures. However, as a general trend, increasing the number of stages in the retentate retreatment section has a lower impact on the overall membrane area than in the permeate retreatment section. 


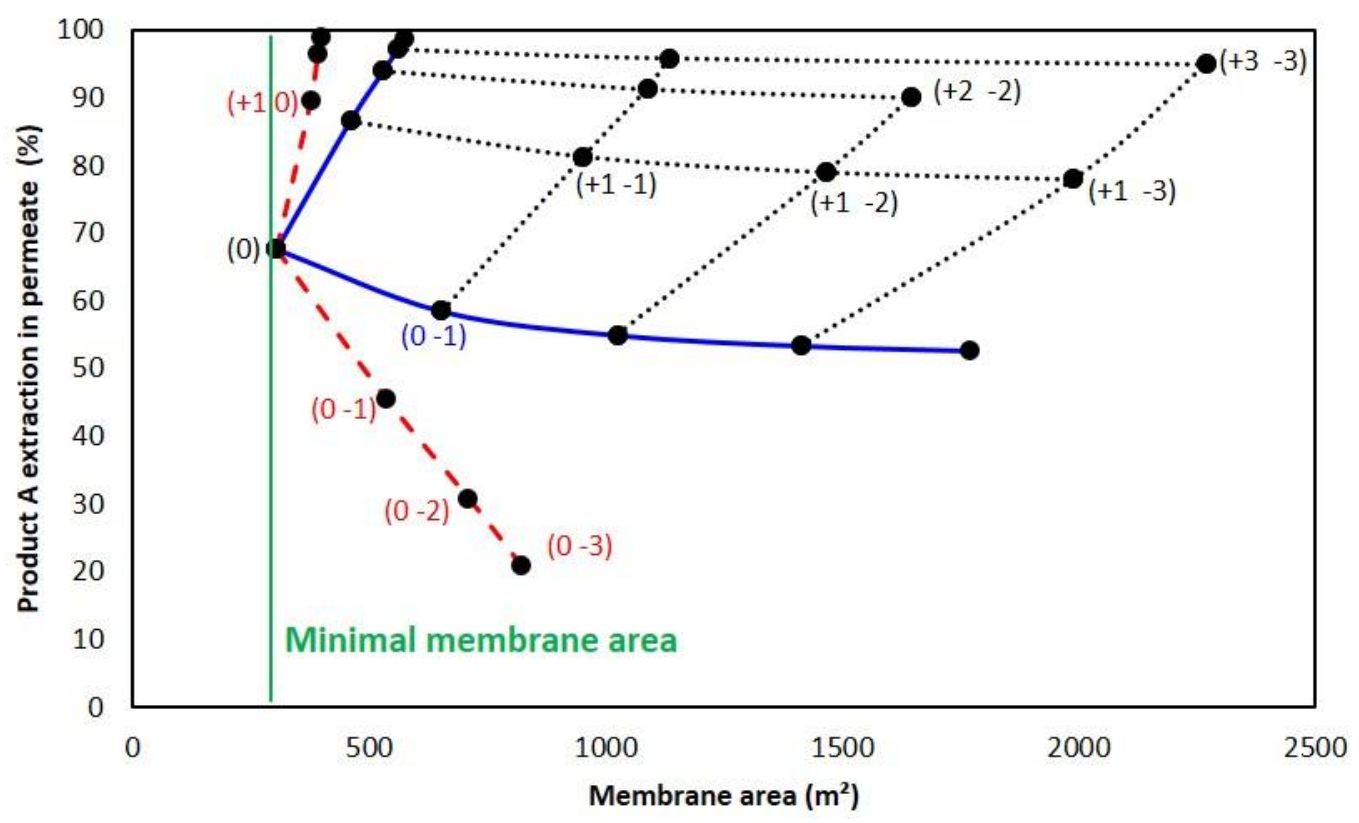

Figure 8: Results of the simulation of membrane cascades (Map 2 with VRR=5 at each stage): permeate extraction of product $\boldsymbol{A}$ in function of membrane area-dashed lines: configurations without recycling - full lines: cascades with recycling with only a retentate or a permeate retreatment section - dotted lines: cascades with recycling with both permeate and retentate retreatment sections.

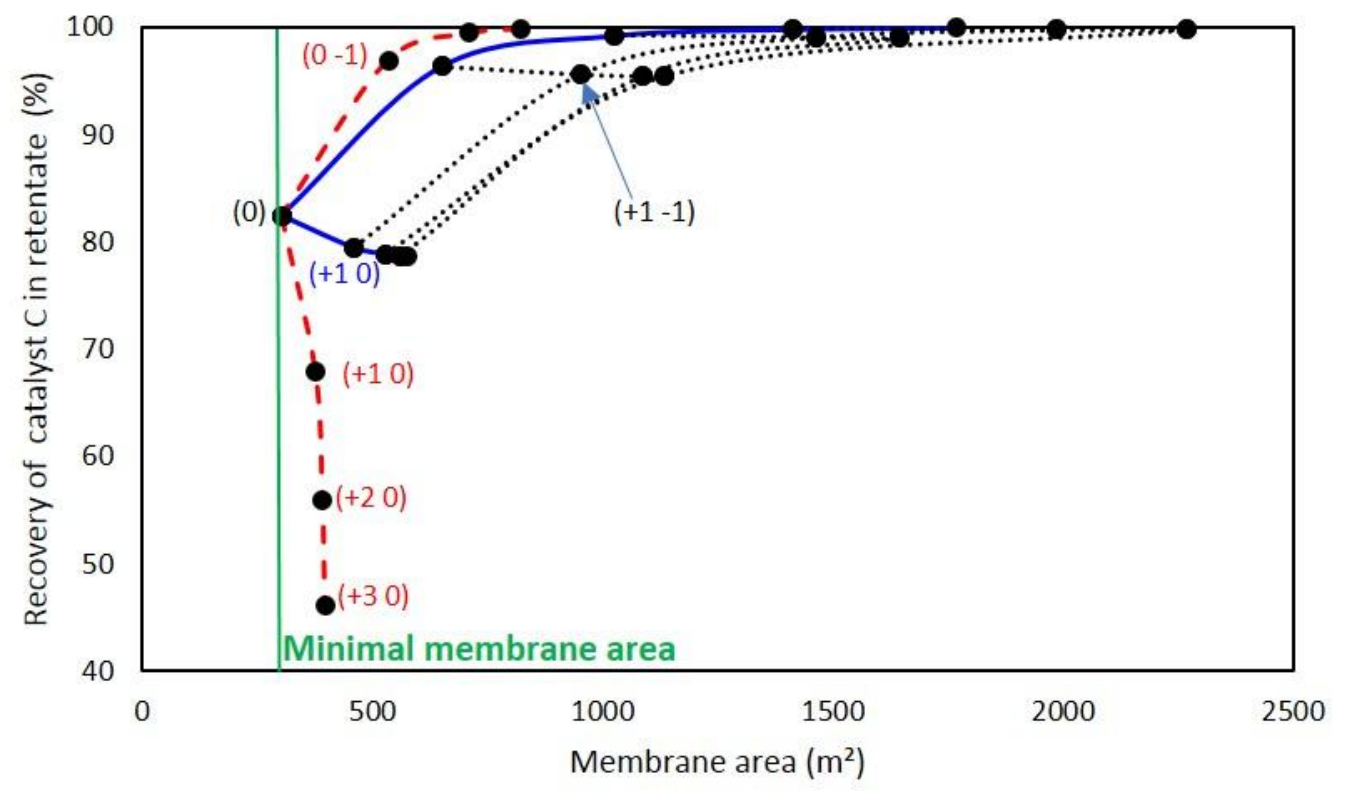

Figure 9: Results of the simulation of membrane cascades (Map 3 with VRR=5 at each stage): retentate recovery of catalyst $\boldsymbol{C}$ in function of membrane area-dashed lines: configurations without recycling - full lines: cascades with recycling with only a retentate or a permeate retreatment section - dotted lines: cascades with recycling with both permeate and retentate retreatment sections. 


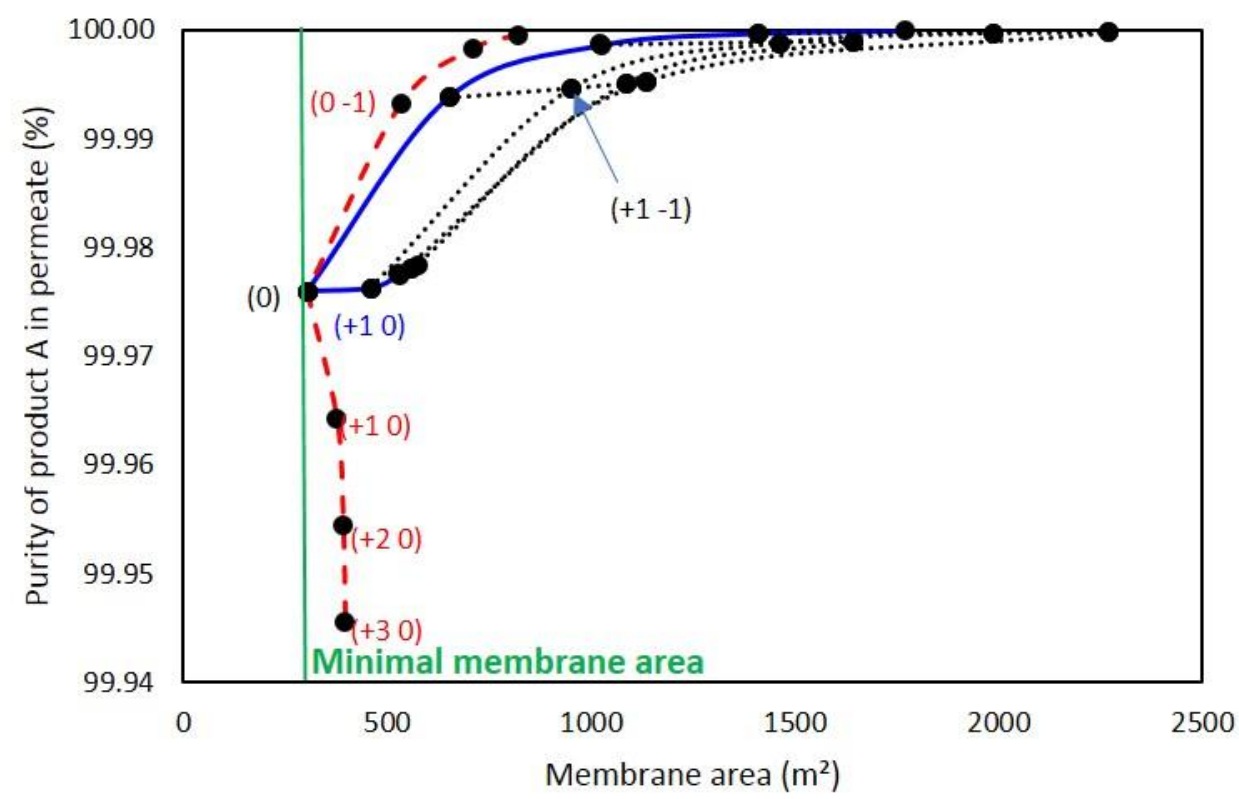

Figure 10: Results of the simulation of membrane cascades (Map 4 with VRR=5 at each stage): permeate purity of product $\boldsymbol{A}$ in function of membrane area-dashed lines: configurations without recycling - full lines: cascades with recycling with only a retentate or a permeate retreatment section - dotted lines: cascades with recycling with both permeate and retentate retreatment sections.

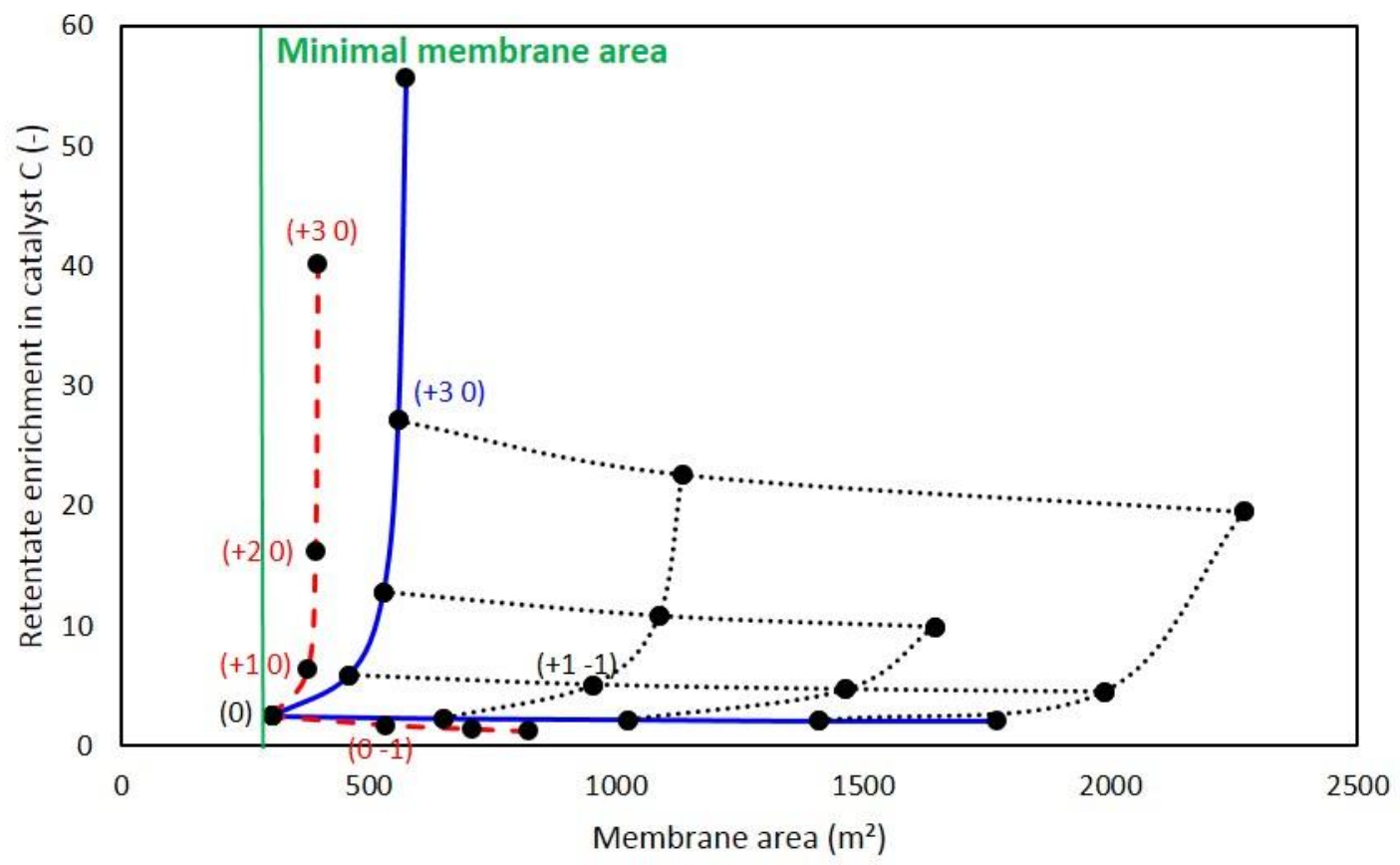

Figure 11: Results of the simulation of membrane cascades (Map 5 with VRR=5 at each stage): retentate enrichment of catalyst $\boldsymbol{C}$ in function of membrane area-dashed lines: 
configurations without recycling - full lines: cascades with recycling with only a retentate or a permeate retreatment section - dotted lines: cascades with recycling with both permeate and retentate retreatment sections.

Finally, the energy consumption was plotted versus the membrane area in Figure 12 on which both minimal membrane area and energy consumption correspond to the one-stage process. Roughly, the energy consumption increased linearly with the membrane filtering area. This is in accordance with Eq. 26 and Eq. 27. Actually, the membrane area depends on the permeate flowrate (Eq. 26) and the energy consumption depends on the feed flowrate (Eq. 27). These 2 flows are in fact linked by the VRR at each stage.

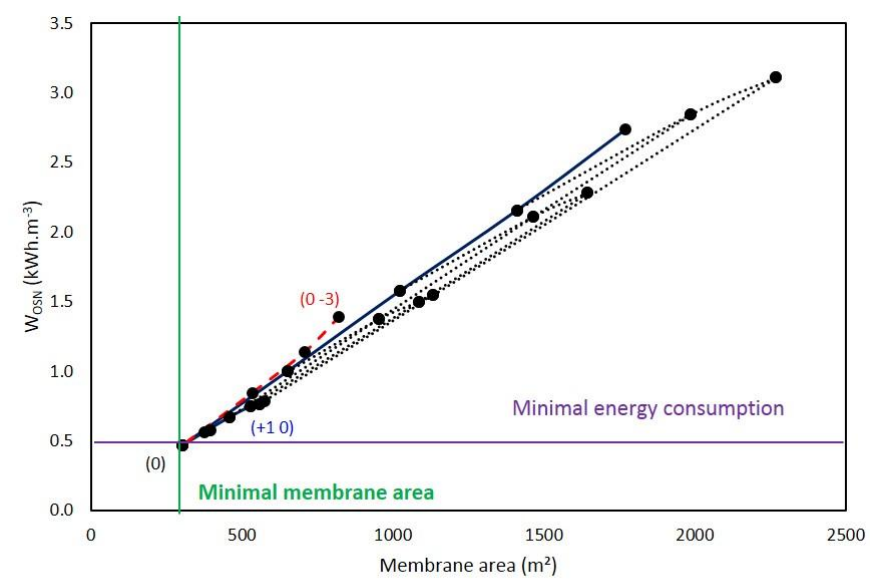

(a)

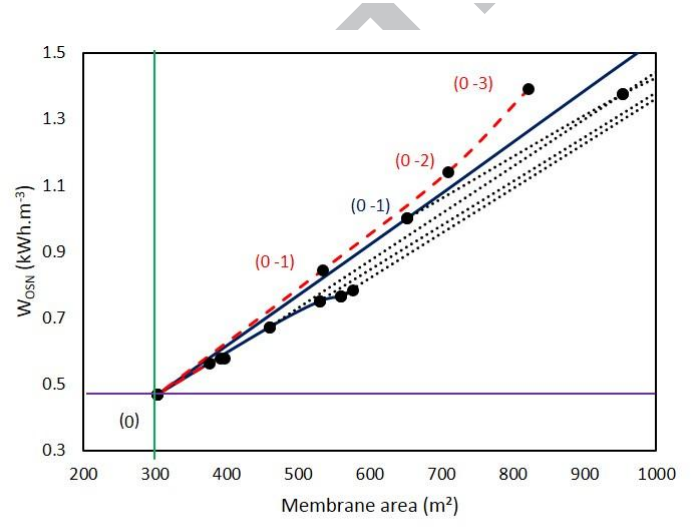

(b)

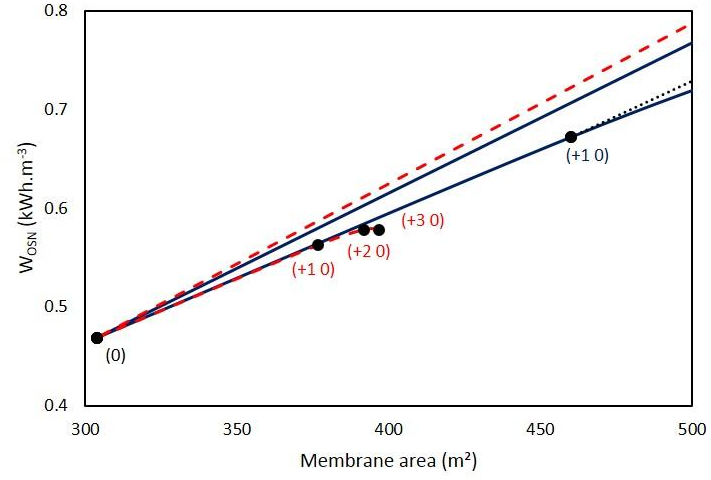

(c)

Figure 12: Results of the simulation of membrane cascades (Map 6 with VRR=5 at each stage): energy consumption in function of membrane area - (a) full scale - (b) and (c) zoomdashed lines: cascades without recycling - full lines: cascades with recycling with only a retentate or a permeate retreatment section - dotted lines: cascades with recycling with both permeate and retentate retreatment sections. 
The analysis of this graphical representation can be sufficient to propose the main compromises. Nevertheless, the help of a multi-criteria optimisation can complete the representation.

\section{Multi-criteria optimisation}

In order to perform a multi-criteria optimisation, all the separation criteria presented above were first described in terms of individual desirability $\left(d_{i}\right)$. This is a dimensionless variable whose scale was the same whatsoever the criterion. $d_{i}$ expressed the satisfaction about a criterion and its value was in the range 0 to $1[33,34]$. A value of 1 means that the criterion was fully reached whereas 0 means that the criterion was not reach at all.

The individual desirability can be used to minimize, maximize or target a value of a criterion (Figure 13).

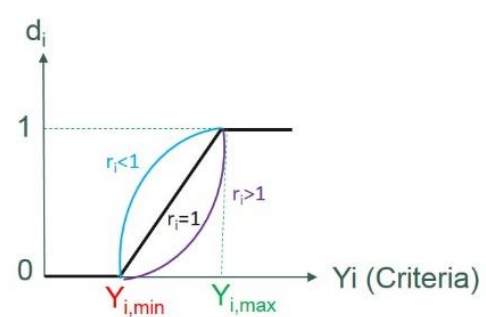

(a)

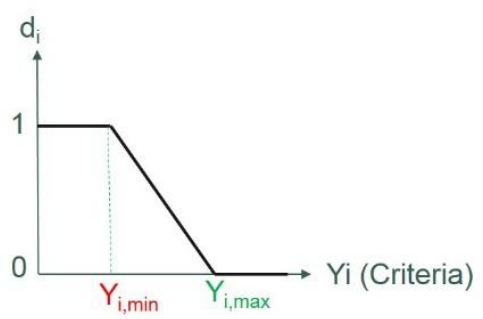

(b)

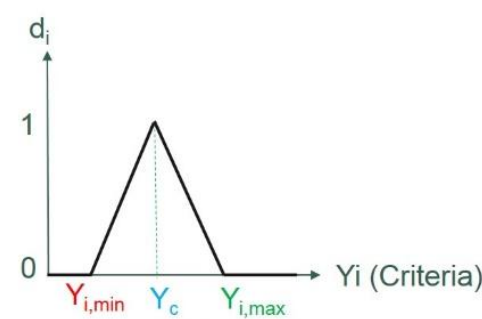

(c)

Figure 13: Individual desirability $d_{i}$ in function of the value of a criterion $Y_{i}-a$ ) Maximize the criterion - b) Minimize the criterion - c) Target value of a criterion. Two particular cases can be used when a limiting value has to be reached. In this case $Y_{i, \min }=Y_{i, \max }$ (Figure 13 a,

Figure $13 \mathrm{~b}$ ) and the value can be either maximized or minimized.

Eq. 30-32 give the individual desirability according to [34, 35]. Appropriate equations were chosen criterion by criterion according to the objective (minimize, maximize, target value).

- Maximize the criterion

$$
\begin{array}{ll}
\text { if } Y_{\mathrm{i}}<\mathrm{Y}_{\mathrm{i}, \mathrm{min}}: & d_{i}=0 \\
\text { if } \mathrm{Y}_{\mathrm{i}, \min } \leq \mathrm{Y}_{\mathrm{i}} \leq \mathrm{Y}_{\mathrm{i}, \max } & d_{i}=\left[\frac{\mathrm{Y}_{\mathrm{i}}-\mathrm{Y}_{\mathrm{i}, \min }}{\mathrm{Y}_{\mathrm{i}, \max }-\mathrm{Y}_{\mathrm{i}, \min }}\right]^{\mathrm{r}_{\mathrm{i}}} \\
\text { if } \mathrm{Y}_{\mathrm{i}}>\mathrm{Y}_{\mathrm{i}, \max }: & d_{i}=1
\end{array}
$$

With:

$Y_{i}$ the value of the criterion 
$Y_{i, \text { min }}$ the value below which $Y_{i}$ is not satisfying $\left(d_{i}=0\right)$

$Y_{i, \max }$ the value above which $Y_{i}$ is fully satisfying $\left(d_{i}=1\right)$

$r_{i}$ a factor modifying the importance of the variation of a given criterion.

In this study $r_{i}$ was taken equal to 1 which means that the variation of the desirability between the minimal and maximal satisfying criteria was linear.

- Minimize the criterion

$$
\begin{array}{ll}
\text { if } \mathrm{Y}_{\mathrm{i}}>\mathrm{Y}_{\mathrm{i}, \max } & d_{i}=0 \\
\text { if } \mathrm{Y}_{\mathrm{i}, \min } \leq \mathrm{Y}_{\mathrm{i}} \leq \mathrm{Y}_{\mathrm{i}, \max } & d_{i}=\left[\frac{\mathrm{Y}_{\mathrm{i}}-\mathrm{Y}_{\mathrm{i}, \max }}{\mathrm{Y}_{\mathrm{i}, \min }-\mathrm{Y}_{\mathrm{i}, \max }}\right]^{\mathrm{r}_{\mathrm{i}}} \\
\text { if } \mathrm{Y}_{\mathrm{i}}<\mathrm{Y}_{\mathrm{i}, \min } & d_{i}=1
\end{array}
$$

With:

$Y_{i, m i n}$ the value below which $Y_{i}$ is fully satisfying $\left(d_{i}=1\right)$

$Y_{i, \max }$ the value above which $Y_{i}$ is not satisfying $\left(d_{i}=0\right)$

- Target value

$$
\begin{array}{ll}
\text { if } \mathrm{Y}_{\mathrm{i}}>\mathrm{Y}_{\mathrm{i}, \max } & d_{i}=0 \\
\text { if } \mathrm{Y}_{\mathrm{i}, \min } \leq \mathrm{Y}_{\mathrm{i}} \leq \mathrm{Y}_{\mathrm{c}} & d_{i}=\left[\frac{\mathrm{Y}_{\mathrm{i}}-\mathrm{Y}_{\mathrm{I}, \mathrm{min}}}{\mathrm{Y}_{\mathrm{c}}-\mathrm{Y}_{\mathrm{I}, \min }}\right]^{\mathrm{r}_{\mathrm{i}}} \\
\text { if } \mathrm{Yi}<\mathrm{Y}_{\mathrm{i}, \min } & d_{i}=0 \\
\text { if } \mathrm{Y}_{\mathrm{c}} \leq \mathrm{Y}_{\mathrm{i}} \leq \mathrm{Y}_{\mathrm{i}, \max } & d_{i}=\left[\frac{\mathrm{Y}_{\mathrm{i}}-\mathrm{Y}_{\mathrm{i}, \max }}{\mathrm{Y}_{\mathrm{c}}-\mathrm{Y}_{\mathrm{i}, \max }}\right]^{\mathrm{r}_{\mathrm{i}}} \\
\text { if } \mathrm{Y}_{\mathrm{c}}=\mathrm{Y}_{\mathrm{i}} & d_{i}=1
\end{array}
$$

\section{With:}

\section{$Y_{c}$ the target value of the criterion}

$Y_{i, \text { min }}$ the value below which $Y_{i}$ is not satisfying $\left(d_{i}=0\right)$

$Y_{i, \max }$ the value above which $Y_{i}$ is not satisfying $\left(d_{i}=0\right)$

Then all the individual desirabilities were gathered in one global desirability (D) which was the geometric mean of all individual desirabilities (Eq. 33) [34].

According to the geometric mean, if any individual desirability was null, the global desirability was null too. It means that if only one criterion was not satisfied, the considered system was rejected even if all the other criteria were fully satisfied. 
The highest value of $\mathrm{D}$ is obtained when the combination of the various criteria is globally optimal.

$$
\mathrm{D}=\left[\prod d_{i}{ }^{\mathrm{w}_{\mathrm{i}}}\right]^{1 / \sum \mathrm{w}_{\mathrm{i}}}
$$

With:

$\mathrm{w}_{\mathrm{i}}$ the weight of the individual desirability

The parameter $\mathrm{w}_{\mathrm{i}}$ permits to weight the importance of each individual desirability.

In the present work, the value of $\mathrm{w}_{\mathrm{i}}$ was arbitrarily always taken equal to 1 so all criteria have the same importance.

\section{Results and discussion}

The result part shows how to use the "graphical representation" to design appropriate cascades according to different objectives facing OSN and in a given case study aiming mainly at a high recovery of the catalyst $\mathbf{C}$.

First of all, it must be strongly underlined that all conclusions in the following are correct only for the used assumptions. The graphical representation is not universal. Only the representation is transposable to other cases. So in the following all conclusions are drawn with this strong restriction.

\subsection{Use of the representation to understand the reachable targets}

Our first objective aims at helping users to understand what is technically feasible with membranes, either in a single step process or in a cascade. Map 1 allows immediately understanding the limitation in the simultaneous recovery of the two components. Map 4 and Map 5 point out the limitation in purity. The graphical representation highlights immediately the need in compromises because it is not possible to simultaneously reach maximum for all criteria.

\subsubsection{Rapid identification of limitation in recovery}

Map 1 in Figure 6 highlights performances dealing with extraction/recovery of $\mathbf{A} / \mathbf{C}$ in permeate/retentate, respectively. Such performances are drawn without any consideration for the fraction quality.

Map 1 at $\mathrm{VRR}=5$ allows immediately understanding the limitation in the simultaneous recovery of the two components. The reading is simple: a solution with maximum 5 -stage cascade exists only if a dot exists on Map 1. Thus, it clearly appears that it would not be possible to integrally extract $\mathbf{A}$ and $\mathbf{C}$ in their respective fractions because no dot (no cascade) 
is superimposed with the "cross" imaging the ideal separation.

The minimum reached values are those obtained with a single stage process (dot "0"). Same conclusions can be drawn from the graphical representations at VRR $=8$ and VRR $=10$ (Map 1 in Figures A2-A3, Appendix 2). Table 3 underlines the limits with the VRR at each stage, either for the minimum or the maximum reachable values (with a maximum of 5 stages).

Table 3: Minima and maxima (\%) in extraction /recovery of $\boldsymbol{A} / \boldsymbol{C}$ in permeate/retentate for OSN one step process with VRR (Figure 6, and Map 1 of Figures A2-A3). Minima corresponds to dot " 0 " on Maps (one-stage process) whereas maxima is the higher value reached with a maximum of 5 stages.

\begin{tabular}{|c|ccc|}
\cline { 2 - 4 } \multicolumn{1}{c|}{} & \multicolumn{3}{c|}{ Simultaneous Recovery (\%) } \\
\cline { 2 - 4 } \multicolumn{1}{c|}{} & $\begin{array}{c}\text { VRR=5 } \\
\text { mini / maxi }\end{array}$ & $\begin{array}{c}\text { VRR }=8 \\
\operatorname{mini} / \text { maxi }\end{array}$ & $\begin{array}{c}\text { VRR }=10 \\
\text { mini / maxi }\end{array}$ \\
\hline A in permeate & $67.6 / 98.9$ & $76.7 / 99.8$ & $80.0 / 99.9$ \\
C in retentate & $82.4 / 99.9$ & $77.9 / 99.6$ & $75.9 / 99.3$ \\
\hline
\end{tabular}

\subsubsection{Rapid identification of limitation in purity}

Map 4 and Map 5 point out the limitations when dealing with the purity of the fractions. For cascades with both permeate and retentate retreatment sections, the minimum reachable values are those obtained with the single stage process (dot " 0 "), depending on VRR. The maximum purity of $\mathbf{A}$ in the permeate is more or less the same regardless of the VRR. The impact of VRR is more significant when dealing with the catalyst $\mathbf{C}$ enrichment in the retentate (Table 4).

Table 4: Minima in purity of $\boldsymbol{A}(\%) /$ enrichment of $\boldsymbol{C}$ in permeate/retentate for OSN one step process with VRR (Figure 9, Figure 10, and Map 4 and 5 of Figures A2-A3). Minima corresponds to dot " 0 " on Maps (one stage process) whereas maxima is the higher value reached with a maximum of 5 stages.

$\begin{array}{ccc}\mathrm{VRR}=5 & \mathrm{VRR}=8 & \mathrm{VRR}=10 \\ \operatorname{mini} / \operatorname{maxi} & \operatorname{mini} / \operatorname{maxi} & \operatorname{mini} / \operatorname{maxi}\end{array}$




\begin{tabular}{|c|ccc|}
\hline A in permeate (purity) & $99.97 />99.9999$ & $99.97 />99.9999$ & $99.97 />99.9999$ \\
C in retentate (enrichment) & $2.5 / 55.7$ & $3.3 / 283.5$ & $3.8 / 486.2$ \\
\hline
\end{tabular}

\subsubsection{Rapid identification based on other criteria}

Of course, the initial use of the graphical representation can also be based on the energy consumption requirement for comparison to classical separation processes. But also with respect to the membrane area as it has an impact on both CAPEX and OPEX. Table 5 shows the minima and maxima values of these two parameters when using a one-stage process (dot " 0 ") and a process with a maximum of 5 stages, regardless of others criteria.

Table 5: Minimum/Maximum membrane area and energy consumption deduced from Maps 26 (Figure 8-12 for VRR= 5, Figures A2-A3 in Appendix for $V R R=8$ and $V R R=10$ ). Minima corresponds to dot " 0 " on Maps (one-stage process) whereas maxima is the higher value reached with a maximum of 5 stages.

\begin{tabular}{|c|ccc|}
\cline { 2 - 4 } \multicolumn{1}{c|}{} & $\begin{array}{c}\mathrm{VRR}=5 \\
\operatorname{mini} / \operatorname{maxi}\end{array}$ & $\begin{array}{c}\mathrm{VRR}=8 \\
\operatorname{mini} / \operatorname{maxi}\end{array}$ & $\begin{array}{c}\mathrm{VRR}=10 \\
\operatorname{mini} / \operatorname{maxi}\end{array}$ \\
\hline Membrane area $\left(\mathrm{m}^{2}\right)$ & $304 / 1988$ & $337 / 1881$ & $348 / 1894$ \\
Energy consumption $\left(\mathrm{kWh} . \mathrm{m}^{-3}\right)$ & $0.5 / 2.8$ & $0.5 / 2.6$ & $0.5 / 2.5$ \\
\hline
\end{tabular}

\subsection{Case study: very high $\mathrm{C}$ recovery (>99\%) and moderate A extraction (>70\%)}

In this section, the recovery of the two components of the mixture to separate remains the focus for sake of an illustration. According to the results in the previous sections, clearly OSN cascades would be efficient to recover the catalyst $\mathbf{C}$. But a high efficiency cannot be fulfilled simultaneously with a very high product A extraction.

Consequently, a less ambitious objective dealing with at least $99 \% \mathbf{C}$ recovery together with a moderate A extraction estimated at least to be $70 \%$ is now discussed.

The objective of the very high catalyst recovery was chosen because of the high cost of both the catalyst and the biphephos ligand but also to lower the metal contamination in the product A that can limit its valorisation.

The extraction of $\mathbf{A}$ has been lowered to $70 \%$ in order to limit the amount that has to be recycled back towards the synthesis reactor. This is not an ambitious target since $70 \%$ is only a little better than what can be reached with a one-step process. This strategy would be acceptable when the product does not poison the reaction as it is the case here. Nevertheless, one must take in consideration that the higher the recycled volume of $\mathbf{A}$ in the synthesis reactor the lower is the remaining volume for the substrate during the next batch reaction. 


\subsubsection{Selection of cascades allowing to fulfill the objectives}

From Map 1 at VRR= 5 (Figure 6), VRR=8 (Figure A-2) and VRR=10 (Figure A-3) six cascades with a maximum of 5 stages fulfilled at least the limiting requirements.

Figure A-4 in Appendix 2 highlights the zoom of Maps 1 and the configurations are given in Table 6. Two cascades with 4 stages were suggested $(+1-2)$ at $\mathrm{VRR}=5$ and $(0-3)$ at $\mathrm{VRR}=$ 10 whereas the four others have 5 stages. Of course, the six cascades have not strictly equivalent performances, some of them can be better than the limiting requirements.

To just fulfill the limiting requirements the $(+1-2)$ cascade at $V R R=5$ appeared as the simplest moreover needing the lowest membrane area (Map 2, Figure 8). Nevertheless the (0 -3) cascade at VRR= 10 (Map 2, Figure A-3, Appendix 2) appeared as a serious competitor with respect to its slightly lower energy consumption but higher membrane area. It is not easy to select one of these two configurations without other arguments.

Table 6: Results of the simulation, the objective being to simultaneously have more than 99\% of catalyst $\boldsymbol{C}$ recovery in the retentate and more than $70 \%$ of product $\boldsymbol{A}$ extraction in the

\begin{tabular}{|c|c|c|c|c|c|c|}
\hline \multirow{2}{*}{$\begin{array}{l}\text { VRR at each stage } \\
\text { Configuration }\end{array}$} & \multicolumn{3}{|c|}{5} & \multirow{2}{*}{$\frac{8}{(+1-3)}$} & \multicolumn{2}{|c|}{10} \\
\hline & $(+1-2)$ & $(+1-3)$ & $(+2-2)$ & & $(0-3)$ & $(+1-3)$ \\
\hline Number of stages & 4 & 5 & 5 & 5 & 4 & 5 \\
\hline Extraction of A (\%) & 79.0 & 78.0 & 90.1 & 90.8 & 75.2 & 93.8 \\
\hline Purity of A (\%) & $>99.99$ & $>99.99$ & $>99.99$ & $>99.99$ & $>99.99$ & $>99.99$ \\
\hline Recovery of C (\%) & 99.1 & 99.8 & 99.0 & 99.4 & 99.3 & 99.1 \\
\hline Enrichment of C (-) & & 4.5 & 10.0 & 10.7 & 4.0 & 15.8 \\
\hline Membrane area $\left(\mathrm{m}^{2}\right)$ & & 1988 & 1645 & 1881 & 1534 & 1837 \\
\hline $\mathrm{W}_{\mathrm{OSN}}\left(\mathrm{kWh} \cdot \mathrm{m}^{-3}\right)$ & 2.1 & 2.8 & 2.3 & 2.4 & 2.0 & 2.3 \\
\hline Global VRR (-) & 16.2 & 16.1 & 65.0 & 49.0 & 9.0 & 81.0 \\
\hline Global desirability & 0.59 & 0.36 & 0 & 0.55 & 0.53 & 0 \\
\hline
\end{tabular}

The multi-criteria optimisation was then applied to the designs suggested in Table 6. Firstly, five criteria were selected including the overall VRR not explicitly taken into account by the graphical representation (but more or less implicitly thanks to the values initially chosen for VRR at each stage). The limiting values for individual desirabilities were chosen from the reachable values highlighted by the various Maps.

Table 7 gives the variation of the individual desirability chosen for each criterion that has to be maximised, minimised or limited to a maximum value. Dealing with the recovery in both fractions, the limiting values for desirability were set at the goals of the separation. The recovery of $\mathbf{C}$ has to be maximised with a limiting value set at $99 \%$ (exact initial requirement) whereas the extraction of $\mathbf{A}$ has to be maximised at a value higher than $70 \%$ (moderate extraction). We assumed that $d_{i}=1$ if the extraction of $\mathbf{A}$ was better than $90 \%$.

The membrane area as well as the energy consumption have of course to be minimised. The limiting values for their individual desirability were set as follows: the highest was chosen as that of a seven-stage cascade $\left(\mathrm{d}_{\mathrm{i}}=0\right)$ and the lowest was assumed to be that of a single-step 
process $\left(\mathrm{d}_{\mathrm{i}}=1\right)$.

Finally, for the global VRR, the limiting value for its individual desirability was arbitrarily set at 50 aiming at proposing a realistic cascade.

Table 7: Multicriteria optimization issue

\begin{tabular}{llll}
\hline criterion & Action on the criterion & $\begin{array}{l}\text { Limiting value } \\
\text { for di }=0\end{array}$ & $\begin{array}{l}\text { Limiting value } \\
\text { for di }=1\end{array}$ \\
\hline Extraction of $\mathbf{A}$ & $\begin{array}{l}\text { maximise } \\
\text { maximise } \\
\text { (limiting value) }\end{array}$ & $\leq 70 \%$ & $\geq 90 \%$ \\
Recovery of $\mathbf{C}$ & $\begin{array}{l}\text { Minimise } \\
\text { Membrane area }\end{array}$ & $\geq 2200 \mathrm{~m}^{2}$ & $\geq 99 \%$ \\
Energy consumption & $\begin{array}{l}\text { minimise } \\
\text { minimise } \\
\text { Global VRR }\end{array}$ & $\geq 3.1 \mathrm{kWh}^{-3}$ & $\leq 304 \mathrm{~m}^{2}$ \\
& (limiting value) & $>50$ & $\leq 0.5 \mathrm{kWh}^{-3}$ \\
\hline
\end{tabular}

Only four cascades suggested in Table 6 have a not null global desirability. This result means that the other simulations did not fulfilled all the goals of the simulation. The global desirability for all cascades was lower than 0.60 . This result means that none of the designs was perfect. The optimisation confirmed that the $(+1-2)$ cascade at VRR=5 and $\left(\begin{array}{ll}0 & -3\end{array}\right)$ at $\mathrm{VRR}=10$ are close. But the first design appeared as slightly better. Despite its five stages, the $(+1-3)$ design at $\mathrm{VRR}=8$ appeared between the two previous ones.

5.2.2. Sensitive analysis of the selected cascade thanks to variation of rejections.

The (+1 -2) design at VRR=5 was identified as the best design with respect to the chosen rejections of $\mathbf{A}$ and $\mathbf{C}$ taken as constant.

To test the robustness of the proposal, two simulations of this design were added to the current study in order to take into account the impact of the variations in rejections that are generally experimentally encountered. Simulations were made again with:

$\circ$ variable rejections for both $\mathbf{A}$ and $\mathbf{C}$, in the range 30\%-20\% for $\mathrm{A}$ and $88 \%-85 \%$ for $\mathrm{C}$, respectively. These values were in accordance with experimental data in a wide range of concentration as explained in $[\mathbf{2 2}, \mathbf{2 7}]$.

$\circ$ constant rejections equal to $19 \%$ and $88 \%$ for $\mathbf{A}$ and $\mathbf{C}$, respectively. This assumption 
take into account the variation of $\mathbf{A}$ rejection with the concentration. The value was chosen to be the average value of that reached in the experimental range.

Table 8 compares results obtained with the three assumptions on rejections. No modification was achieved for flux as the variation was already taken into account in the first set of data of Table 2.

Roughly dealing with membrane area and energy consumption, only little differences were highlighted. The same finding can be noticed for the purity of $\mathbf{A}$ in the permeate that remains higher that $99.99 \%$ in each simulation. Small differences appear for the recovery of $\mathbf{C}$ in the retentate ( 0.3 percent point at the most) because the rejection of this solute remains almost the same whatsoever the composition of the mixture to filtrate. The main differences deal with the product extraction and therefore the enrichment of $\mathbf{C}$ in retentate which highly depends on $\mathbf{A}$ extraction. The extraction was lowest in Case $1(\operatorname{Ret}(\mathbf{A})=30 \%)$ and highest in Case 3 $(\operatorname{Ret}(\mathbf{A})=19 \%)$. These results are consistent because the lower the rejection, the higher is the permeate extraction. Case 2 is between the 2 others because actually, the rejection varies between $30 \%$ and $20 \%$ in this simulation. There are around 4 percent points of difference between the simplified simulations detailed in this study (with constant A rejection) and the more accurate simulation varying the rejection. All these results confirm the good quality of the initial simulations and the appropriateness of the graphical representation.

Table 8: Results of the simulation of the (+1-2) design at VRR $=5$ for different assumptions on $\boldsymbol{A}$ and $\boldsymbol{C}$ rejections

\begin{tabular}{lccc}
\hline & Case 1 & Case 2* & Case 3 \\
\hline A rejection (\%) & 30 & $30-20$ & 19 \\
\hline C rejection (\%) & 88 & $88-85$ & 88 \\
\hline Extraction of A in permeate (\%) & 79.0 & 82.9 & 86.7 \\
Purity of A in permeate (\%) & $>99.99$ & $>99.99$ & $>99.99$ \\
Recovery of C in retentate (\%) & 99.1 & 98.8 & 99.1 \\
Enrichment of C in retentate (-) & 4.7 & 5.8 & 7.4 \\
Membrane area (m ${ }^{2}$ ) & 1465 & 1420 & 1392 \\
$\mathrm{~W}_{\text {osN }}\left(\mathrm{kWh} . \mathrm{m}^{-3}\right.$ ) & 2.1 & 2.1 & 2.1 \\
Global desirability & 0.59 & 0.0 & 0.68 \\
\hline
\end{tabular}

*Rejections of $\mathbf{A}$ and $\mathbf{C}$ vary according to the data in $[\mathbf{2 2 , 2 7 ]}$

\section{Conclusion}

This paper proposes a "graphical representation" made of several 2D-maps to help the membrane end-user to understand what can be obtained with membrane cascades.

The separation of the final media of hydroformylation of 10-undecenitrile in toluene by 
organic solvent nanofiltration was chosen as an example. Only the separation of two components was considered in order to simplify the study while the real media is much more complex. Thus, the most difficult separation was selected in order to propose cascade designs taking into account many compromises that have been firstly highlighted and secondly solved. The different compromises reported here were the quality and the recovery yield of each fraction/component together with the energy consumption and the membrane area required to reach the objectives.

This representation required first the systematic simulation of cascades of pre-selected configurations. We voluntary assumed the a priori limitation of the number of stages to 5, anticipating that more complex cascades will probably be too expensive either for investment or operating costs.

The graphical representation is based on sets of six 2D-maps highlighting the relationships between six criteria selected in an appropriate way: extraction/recovery, retentate/permeate quality/purity, membrane filtering area and overall energy consumption.

The 2D-maps highlighted in an easy way several designs of cascades aiming at the recovery of at least $99 \%$ of the catalytic system (C) and the extraction of at least $70 \%$ of the products (A). Moreover, compromises were evidenced when focusing on the membrane area and energy consumption whose variations are significant between different cascade designs that fulfill the desired yields of recovery. In a second time, a multi-criteria optimization was made based on the desirability index in order to fine-tune the choice of the best cascade among those found thanks to the "graphical representation".

Of course, this representation can be used to highlight performances that can be reached when selecting other targets with the same system.

\section{Acknowledgements}

The authors thank the French National Agency for Research (ANR - France) for the financial support of the project MemChem $n^{\circ}$ 14-CE06-0022 and the French clusters IAR and Axelera for labelling this project.

\section{Glossary/Nomenclature}
$\operatorname{Abt}_{\mathrm{i}}(\mathrm{X})$
$\mathrm{A}_{\mathrm{mb}}$
Abatement of solute $\mathrm{X}$ at stage $\mathrm{i}(\%)$
$\mathrm{C}_{\mathrm{F}}(\mathrm{X})$
Membrane filtering area $\left(\mathrm{m}^{2}\right)$
$\mathrm{C}_{\mathrm{F}, \mathrm{i}}(\mathrm{X})$
Feed concentration of the cascade of solute $\mathrm{X}\left(\mathrm{mol} . \mathrm{L}^{-1}\right)$
$\mathrm{C}_{\mathrm{P}, \mathrm{i}, \mathrm{t}}(\mathrm{X})$
Feed concentration at stage i of solute $\mathrm{X}\left(\mathrm{mol} . \mathrm{L}^{-1}\right)$
$\overline{\mathrm{C}_{\mathrm{P}, \mathrm{I}}(\mathrm{X})}$
Permeate concentration at stage $\mathrm{i}$ of solute $\mathrm{X}$ at $\mathrm{t}$ time $\left(\mathrm{mol} . \mathrm{L}^{-1}\right)$
$\mathrm{C}_{\mathrm{R}, \mathrm{i}, \mathrm{t}}(\mathrm{X})$
Permeate average concentration at stage $i$ of solute $X\left(m o l . L^{-1}\right)$
$\mathrm{C}_{\mathrm{R}, \mathrm{i}}(\mathrm{X})$
Retentate concentration at stage $\mathrm{i}$ of solute $\mathrm{X}$ at $\mathrm{t}$ time $\left(\mathrm{mol} \cdot \mathrm{L}^{-1}\right)$
Retentate concentration of solute $\mathrm{X}$ leaving stage $\mathrm{i}\left(\mathrm{mol} . \mathrm{L}^{-1}\right)$ 


\begin{tabular}{|c|c|}
\hline$\overline{\mathrm{C}_{\mathrm{R}, \mathrm{l}}(\mathrm{X})}$ & Retentate average concentration at stage $\mathrm{i}$ of solute $\mathrm{X}\left(\mathrm{mol} . \mathrm{L}^{-1}\right)$ \\
\hline $\mathrm{d}_{\mathrm{i}}$ & Individual desirability (-) \\
\hline $\mathrm{D}$ & Global desirability (-) \\
\hline$Q_{F}$ & Feed flowrate of the cascade $\left(\mathrm{L} \cdot \mathrm{h}^{-1}\right)$ \\
\hline $\mathrm{Q}_{\mathrm{F}, \mathrm{i}}$ & Feed flowrate at stage i $\left(L \cdot h^{-1}\right)$ \\
\hline $\mathrm{Q}_{\mathrm{P}, \mathrm{i}}$ & Permeate flowrate at stage i $\left(\mathrm{L} \cdot \mathrm{h}^{-1}\right)$ \\
\hline$Q_{R, i}$ & Retentate flowrate at stage i $\left(\mathrm{L} . \mathrm{h}^{-1}\right)$ \\
\hline $\mathrm{L}_{\mathrm{P}}$ & Membrane permeance $\left(\mathrm{L} \cdot \mathrm{m}^{-2} \cdot \mathrm{h}^{-1} \cdot \mathrm{bar}^{-1}\right)$ \\
\hline $\operatorname{Ret}_{\mathrm{i}}(\mathrm{X})$ & Average Rejection of solute $\mathrm{X}$ at stage i (\%) \\
\hline$r_{i}$ & Factor modifying the importance of a variation of a criterion \\
\hline TMP & TransMembrane Pressure (bar) \\
\hline $\mathrm{VRR}_{\mathrm{i}}$ & Volume Reduction Ratio at stage i (-) \\
\hline $\mathrm{w}_{\mathrm{i}}$ & Parameter to weigh the importance of each individual desirability \\
\hline $\mathrm{W}_{\mathrm{OSN}}$ & Global pumping energy $\left(\mathrm{kWh} \cdot \mathrm{m}^{-3}\right)$ \\
\hline $\mathrm{Y}_{\mathrm{c}}$ & Target value of the criterion \\
\hline$Y_{i}$ & Value of the criterion \\
\hline$Y_{i, \min }$ & Limiting value to calculate the individual desirability \\
\hline$Y_{i, \max }$ & Limiting value to calculate the individual desirability \\
\hline$\eta_{\text {pump }}$ & Pump efficiency (-) \\
\hline
\end{tabular}

\section{Appendices}

\section{Appendix 1: integration of retentate concentration over a stage to get the abatement}

In steady-state flow and for one solute, 2 mass balances equations can be written:

Solvent mass balance:

$Q_{F}=Q_{P}+Q_{R}$

Solute mass balance:

$\mathrm{Q}_{\mathrm{F}} \times \mathrm{C}_{\mathrm{F}}=\mathrm{Q}_{\mathrm{P}} \times \mathrm{C}_{\mathrm{P}}+\mathrm{Q}_{\mathrm{R}} \times \mathrm{C}_{\mathrm{R}}$

Considering the 2 above equations and using the VRR, one gets:

$\mathrm{C}_{\mathrm{R}}=\frac{\mathrm{C}_{\mathrm{F}}-\left(1-\frac{1}{\mathrm{VRR}}\right) \times \mathrm{C}_{\mathrm{P}}}{\frac{1}{\mathrm{VRR}}}$

A nanofiltration module can be divided into an infinite number of small elements (Fig. A-1). In a small element starting from the module feed until a volume permeation ratio equal to vrr, Eq. A-3 becomes: 
$\mathrm{C}_{\mathrm{R}}^{\prime}=\frac{\mathrm{C}_{\mathrm{F}}-\left(1-\frac{1}{\mathrm{vrr}}\right) \times \mathrm{C}_{\mathrm{P}}^{\prime}}{\frac{1}{\mathrm{vrr}}}$

With $\mathrm{C}_{\mathrm{F}}<\mathrm{C}_{\mathrm{R}}^{\prime}<\mathrm{C}_{\mathrm{R}}$

The permeate concentration can also be calculated incorporating the rejection Ret which is assumed to be constant over the vrr:

$\mathrm{C}_{\mathrm{p}}^{\prime}=\frac{1}{1-\frac{1}{\mathrm{vrr}}} \times \int \mathrm{C}_{\mathrm{P}}^{*} \times \mathrm{d}\left(1-\frac{1}{\mathrm{vrr}}\right)=\frac{1}{1-\frac{1}{\mathrm{vrr}}} \times \int(1-\mathrm{Ret}) \times \mathrm{C}_{\mathrm{R}}^{*} \times \mathrm{d}\left(1-\frac{1}{\mathrm{vrr}}\right)$

With $\mathrm{C}_{\mathrm{P}}^{*}$ and $\mathrm{C}_{\mathrm{R}}^{*}$ the local permeate and local retentate concentrations in a small element of membrane, respectively.

Eq. A-4 and A-5 give:

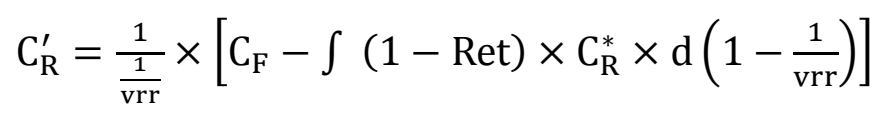

After derivation of Eq. A-6 according to $\left(1-\frac{1}{\text { vrr }}\right)$, one gets:

$\frac{\mathrm{d}\left[\mathrm{C}_{\mathrm{R}}^{\prime} \times \frac{1}{\mathrm{vrr}}\right]}{\mathrm{d}\left(1-\frac{1}{\mathrm{vrr}}\right)}=\frac{\mathrm{dC}_{\mathrm{F}}}{\mathrm{d}\left(1-\frac{1}{\mathrm{vrr}}\right)}-(1-\mathrm{Ret}) \times \mathrm{C}_{\mathrm{R}}^{\prime}$

In Eq. A-7, $\frac{\mathrm{dC}_{\mathrm{F}}}{\mathrm{d}\left(1-\frac{1}{\mathrm{vrr}}\right)}=0$.

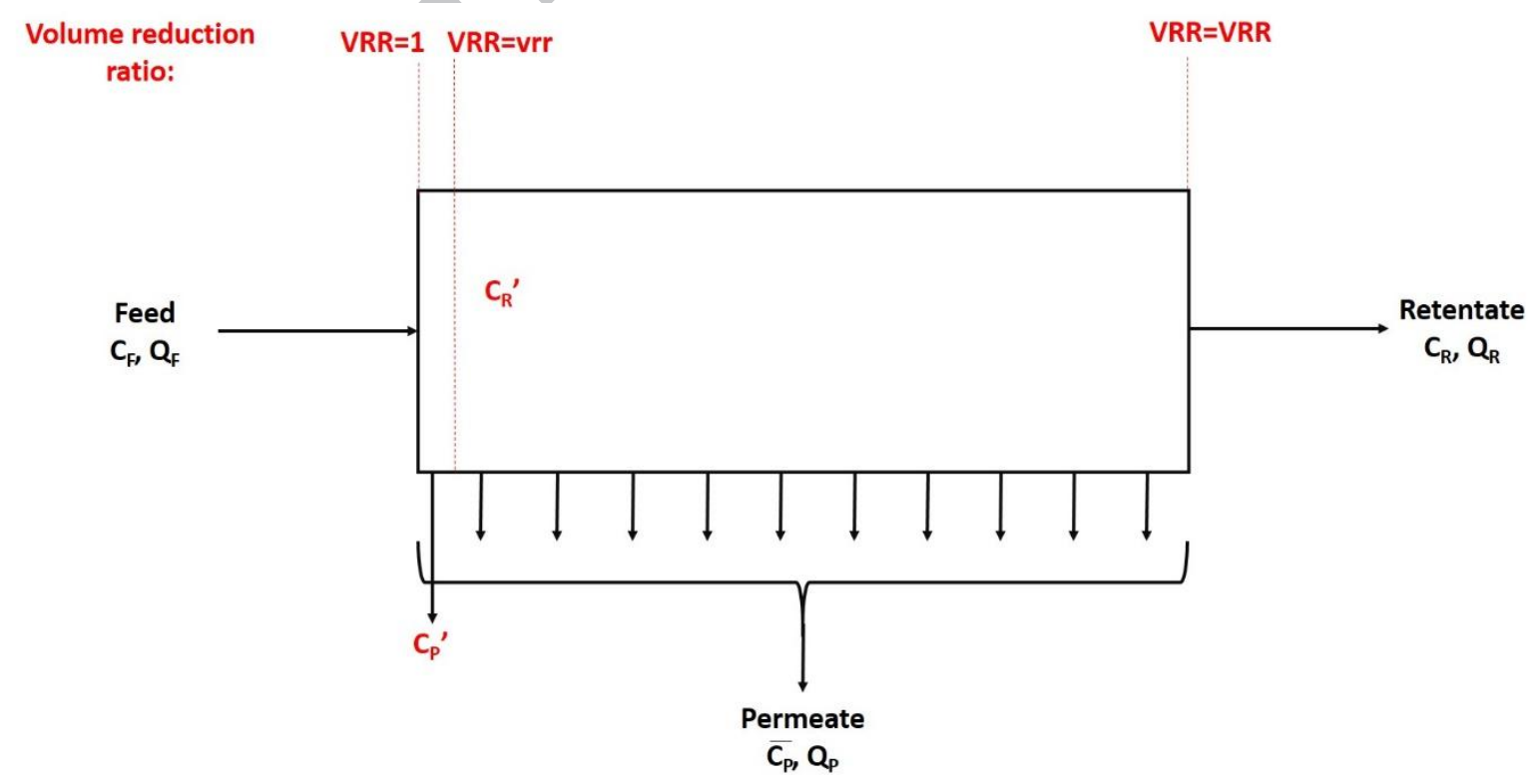

Figure A-1: Nanofiltration module divided into small elements

The derivation can also be expressed by Eq. A-8. 
$\frac{\mathrm{d}\left[\mathrm{C}_{\mathrm{R}}^{\prime} \times \frac{1}{\mathrm{vrr}}\right]}{\mathrm{d}\left(1-\frac{1}{\mathrm{vrr}}\right)}=\frac{1}{\mathrm{vrr}} \times \frac{\mathrm{dC}_{\mathrm{R}^{\prime}}}{\mathrm{d}\left(1-\frac{1}{\mathrm{vrr}}\right)}+\mathrm{C}_{\mathrm{R}}{ }^{\prime} \times \frac{\mathrm{d}\left(\frac{1}{\mathrm{vrr}}\right)}{\mathrm{d}\left(1-\frac{1}{\mathrm{vrr}}\right)}=\frac{1}{\mathrm{vrr}} \times \frac{\mathrm{dC}_{\mathrm{R}^{\prime}}}{\mathrm{d}\left(1-\frac{1}{\mathrm{vrr}}\right)}-\mathrm{C}_{\mathrm{R}}{ }^{\prime}$

Hence combining Eq. A-7 and A-8 leads to:

$\frac{\mathrm{dC}_{\mathrm{R}^{\prime}}}{\mathrm{d}\left(1-\frac{1}{\mathrm{vrr}}\right)}=\frac{\text { Ret } \times \mathrm{C}_{\mathrm{R}^{\prime}}}{\frac{1}{\mathrm{vrr}}}$

Eq. A-9 has to be integrated from the feed to the retentate concentration and from 1 to VRR.

$\int_{C_{F}}^{C_{R}} \frac{d_{C_{R^{\prime}}}}{C_{R^{\prime}}}=-\int_{1}^{1 / \text { VRR }} \frac{\text { Ret } \times d\left(\frac{1}{v r r}\right)}{\frac{1}{v r r}}$

After integration, one gets, with the assumption of constant rejection:

$\ln \left(C_{R}\right)-\ln \left(C_{F}\right)=-\operatorname{Ret} \times\left[\ln \left(\frac{1}{V R R}\right)-\ln (1)\right]$

Eq. A-11 can be rewritten to get Eq. A-12.

$\mathrm{C}_{\mathrm{R}}=\mathrm{C}_{\mathrm{F}} \times\left(\frac{1}{\mathrm{VRR}}\right)^{-\mathrm{Ret}}$

Which can be rewritten as:

$\mathrm{C}_{\mathrm{R}}=\mathrm{C}_{\mathrm{F}} \times \mathrm{VRR}^{\mathrm{Ret}}$

Using the definition of the rejection leads to Eq. A-14.

$\mathrm{C}_{\mathrm{P}}=\mathrm{C}_{\mathrm{F}} \times(1-\mathrm{Ret}) \times \mathrm{VRR}^{\mathrm{Ret}}$

But $C_{P}$ varies in the filtration module and so the average concentration in the permeate has to be used.

Actually, Eq. A-2 (solute mass balance) is modified using an average value of the permeate concentration (calculated by Eq. A-5) because of our assumption of cross-plug flow:

$Q_{F} \times C_{F}=Q_{P} \times \overline{C_{P}}+Q_{R} \times C_{R}$

And Eq. A-4 becomes A-16:

$\mathrm{C}_{\mathrm{R}}=\frac{\mathrm{C}_{\mathrm{F}}-\left(1-\frac{1}{\mathrm{VRR}}\right) \times \overline{\mathrm{C}_{\mathrm{P}}}}{\frac{1}{\mathrm{VRR}}}$

With Eq. A-13 and A-16:

$C_{F} \times V_{R R}^{R e t}=\frac{C_{F}-\left(1-\frac{1}{V R R}\right) \times \overline{C_{P}}}{\frac{1}{V R R}}$

Which gives: 
$\overline{C_{P}}=\frac{C_{F}}{1-\frac{1}{V R R}} \times\left[1-\left(\frac{1}{V R R}\right)^{(1-R e t)}\right]$

Eq. A-18 can be rearranged to give the abatement (Eq. A-19).

Abatement $=1-\frac{\overline{C_{P}}}{C_{F}}=1-\frac{1}{1-\frac{1}{V R R}} \times\left[1-\left(\frac{1}{V R R}\right)^{(1-R e t)}\right]$ 


\section{Appendix 2: Graphical representations at $V R R=8$ and $V R R=10$}
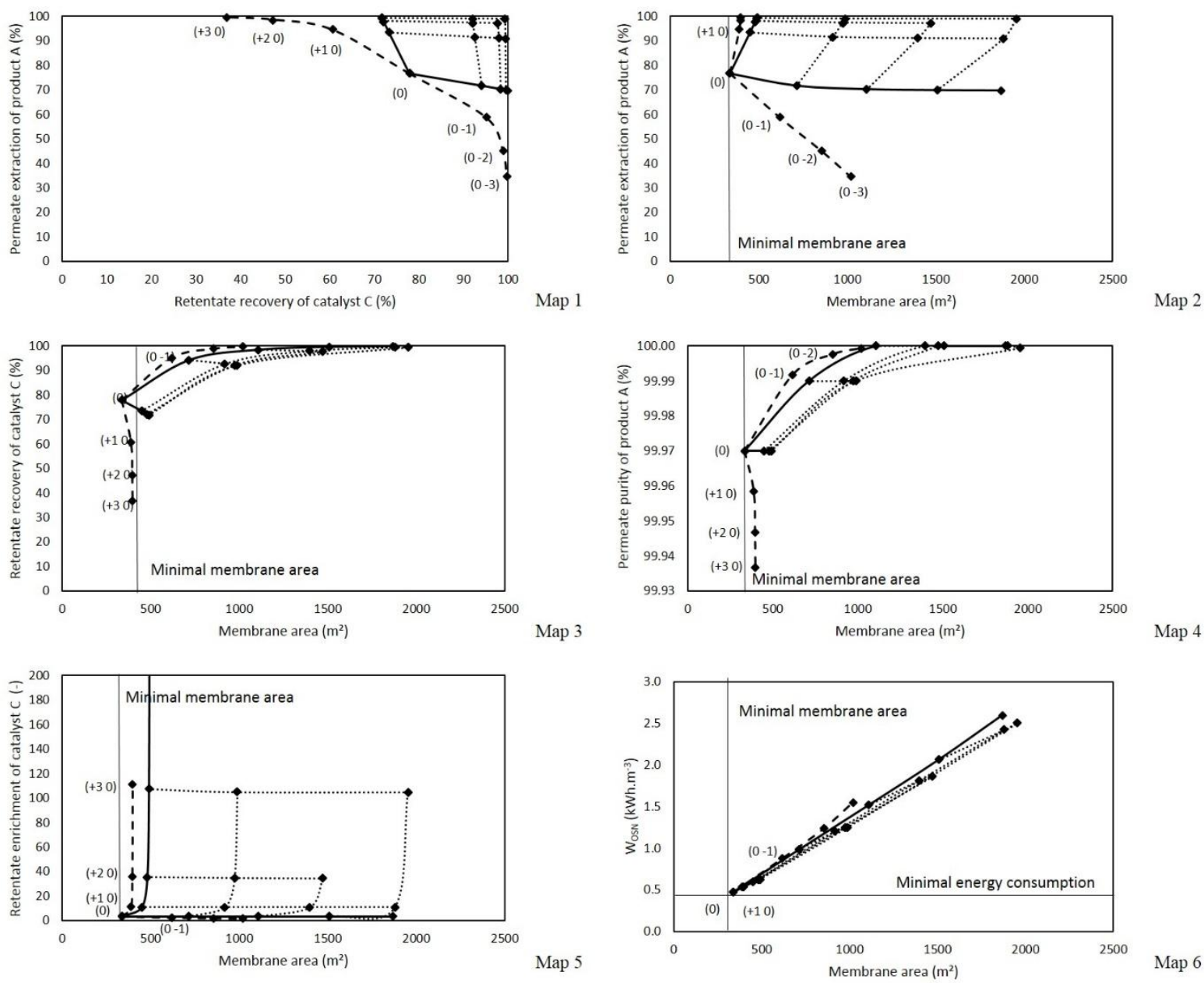

Figure A-2: Example of the overall graphical representation at VRR=8. Each dot corresponds to a cascade design-dashed lines: cascades without recycling - full lines: cascades with recycling with only a retentate or a permeate retreatment section - dotted lines: cascades with recycling with both permeate and retentate retreatment sections. 

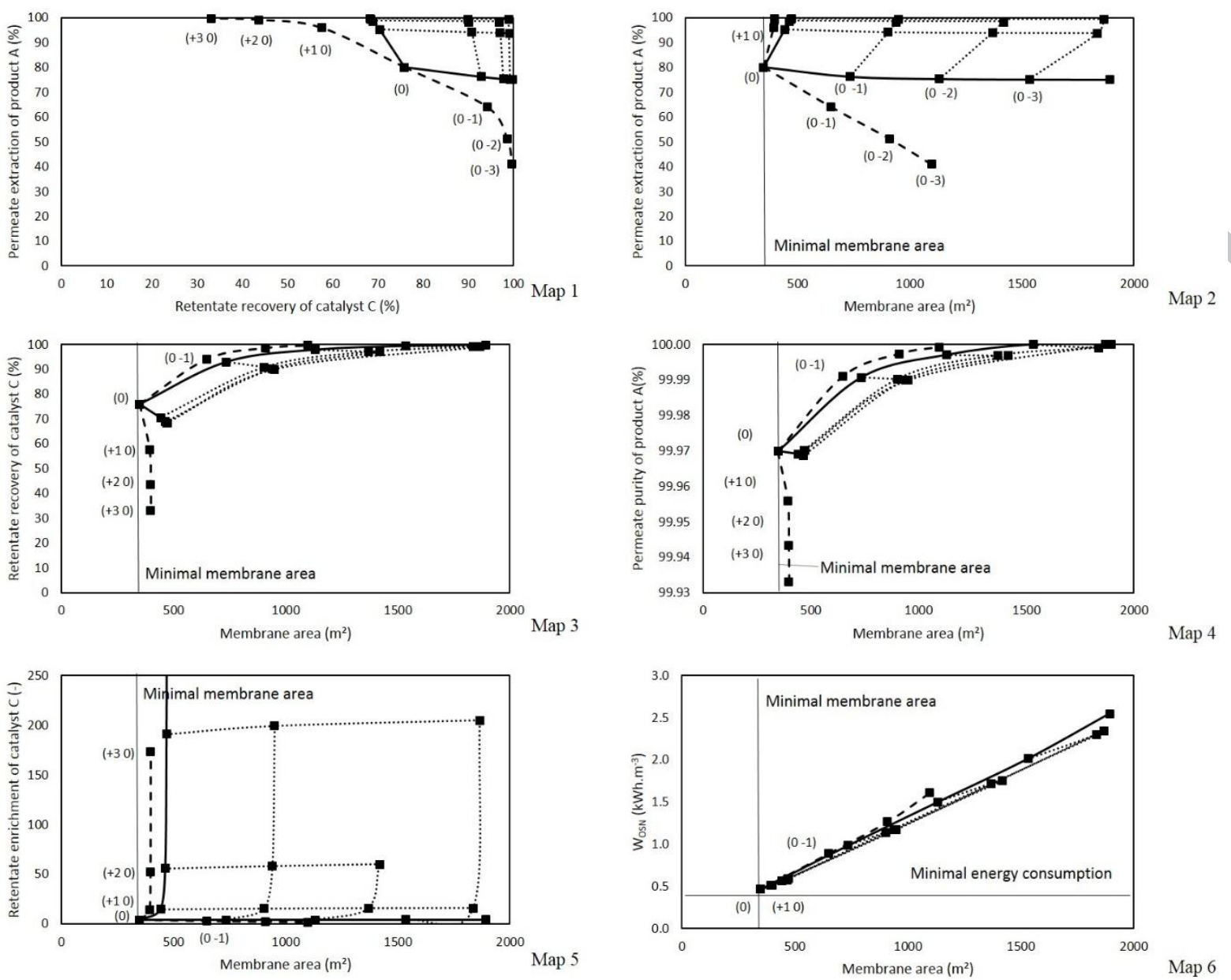

Figure A-3: Example of the overall graphical representation at VRR=10. Each dot corresponds to a cascade design-dashed lines: cascades without recycling - full lines: cascades with recycling with only a retentate or a permeate retreatment section - dotted lines: cascades with recycling with both permeate and retentate retreatment sections. 


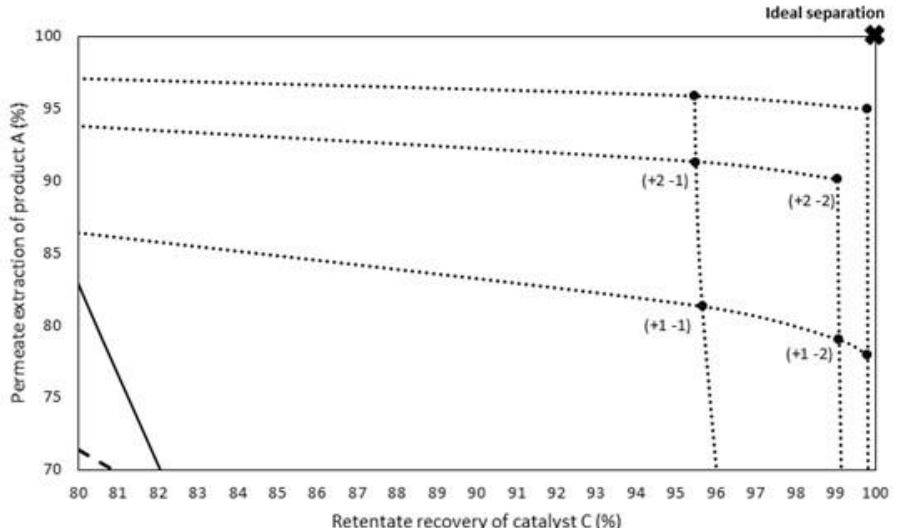

$\mathrm{VRR}=5$

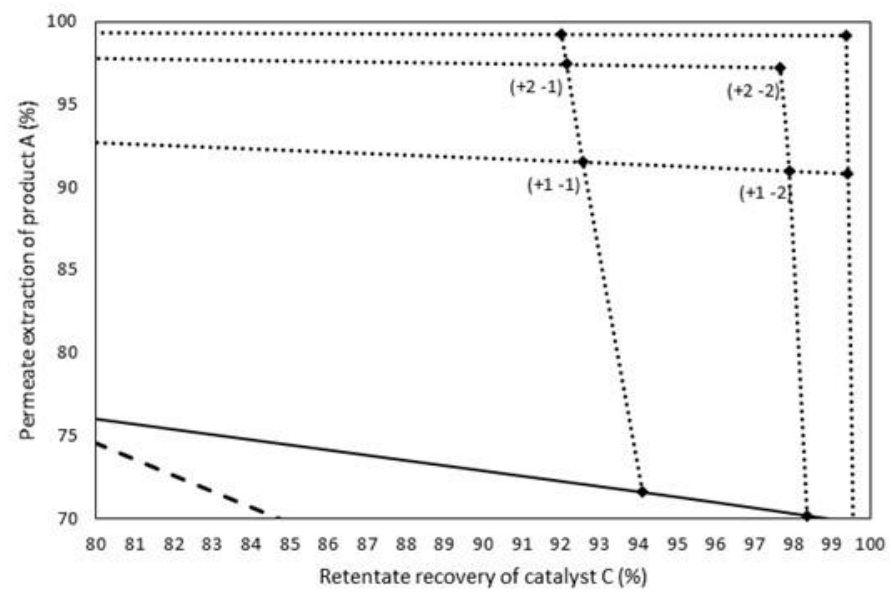

$\mathrm{VRR}=8$

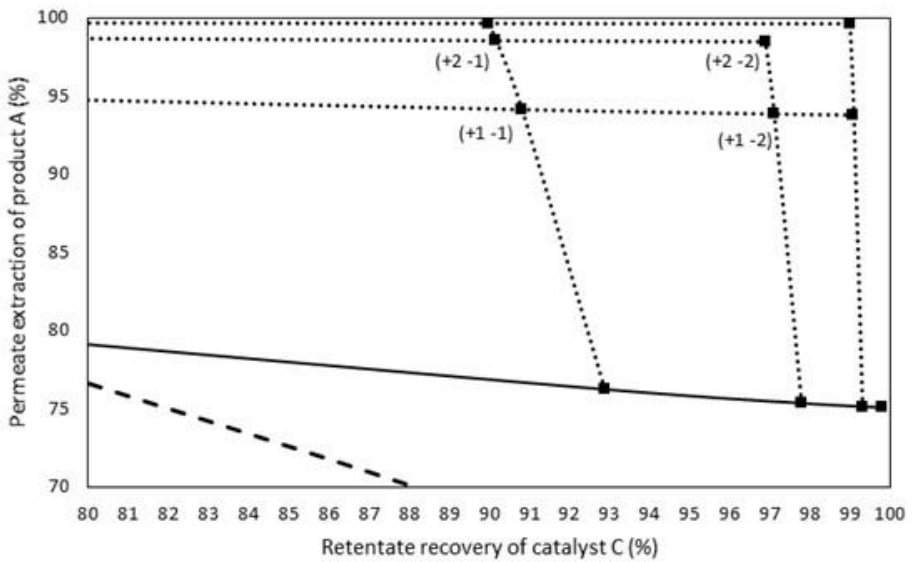

$$
\mathrm{VRR}=10
$$

Figure A-4: Results of the simulation of membrane cascades dealing with the case study, the objectives of which were at least $99 \%$ recovery of $\boldsymbol{C}$ and $70 \%$ extraction of $\boldsymbol{A}$, simultaneously. Zoom on the interesting part of Map 1 (Figure 6, Figure A-2 and Figure A-3) for the three $V R R$,

each dot corresponds to a cascade design. Dashed lines: cascades without recycling (first limiting curve) - full lines: cascades with recycling with only a retentate or a permeate retreatment section (second limiting curve) - dotted lines: cascades with recycling with both permeate and retentate retreatment sections. 


\section{References}

[1] Anastas, P. T.; Warner, J. C. Green Chemistry: Theory and Practice, Oxford University Press: New York, 1998

[2] J. Dreimann, P. Lutze, M. Zagajewski, A. Behr, A. Górak, A.J. Vorholt, Highly integrated reactor-separator systems for the recycling of homogeneous catalysts, Chem. Eng. Process. Process Intensif. 99 (2016) 124-131.

[3] D. Nair, J.T. Scarpello, L.S. White, L.M. Freitas dos Santos, I.F.J. Vankelecom, A.G. Livingston, Semi-continuous nanofiltration-coupled Heck reactions as a new approach to improve productivity of homogeneous catalysts, Tetrahedron Lett. 42(2001) 8219-8222.

[4] A. Datta, K. Ebert, H. Plenio, Nanofiltration for Homogeneous Catalysis Separation: Soluble Polymer-Supported Palladium Catalysts for Heck, Sonogashira, and Suzuki Coupling of Aryl Halides, Organometallics. 22 (2003) 4685-4691.

[5] G. Nasser, T. Renouard, S. Shahane, C. Fischmeister, C. Bruneau, M. Rabiller-Baudry, Interest of the Precatalyst Design for Olefin Metathesis Operating in a Discontinuous Nanofiltration Membrane Reactor, ChemPlusChem. 78 (2013) 728-736.

[6] S. Aerts, A. Buekenhoudt, H. Weyten, L.E.M. Gevers, I.F.J. Vankelecom, P.A. Jacobs, The use of solvent resistant nanofiltration in the recycling of the Co-Jacobsen catalyst in the hydrolytic kinetic resolution (HKR) of epoxides, J. Membr. Sci. 280 (2006) 245-252.

[7] M. Rabiller-Baudry, G. Nasser, T. Renouard, D. Delaunay, M. Camus, Comparison of two nanofiltration membrane reactors for a model reaction of olefin metathesis achieved in toluene, Sep. Purif. Technol. 116 (2013) 46-60.

[8] L. Peeva, J. Arbour, A. Livingston, On the Potential of Organic Solvent Nanofiltration in Continuous Heck Coupling Reactions, Org. Process Res. Dev. 17 (2013) 967-975.

[9] A. Keraani, T. Renouard, C. Fischmeister, C. Bruneau, M. Rabiller-Baudry, Recovery of enlarged olefin metathesis catalysts by nanofiltration in an eco-friendly solvent, ChemSusChem. 1 (2008) 927-933.

[10] J. Guerra, D. Cantillo, C.O. Kappe, Visible-light photoredox catalysis using a macromolecular ruthenium complex: reactivity and recovery by size-exclusion nanofiltration in continuous flow, Catal. Sci. Technol. 6 (2016) 4695-4699.

[11] R. Abejón, A. Garea, A. Irabien, Analysis and optimization of continuous organic solvent nanofiltration by membrane cascade for pharmaceutical separation, AIChE J. 60 (2014) 931-948. 
[12] W.E. Siew, A.G. Livingston, C. Ates, A. Merschaert, Molecular separation with an organic solvent nanofiltration cascade - augmenting membrane selectivity with process engineering, Chem. Eng. Sci. 90 (2013) 299-310.

[13] W.E. Siew, A.G. Livingston, C. Ates, A. Merschaert, Continuous solute fractionation with membrane cascades - A high productivity alternative to diafiltration, Sep. Purif. Technol. 102 (2013) 1-14.

[14] J.C.-T. Lin, A.G. Livingston, Nanofiltration membrane cascade for continuous solvent exchange, Chem. Eng. Sci. 62 (2007) 2728-2736.

[15] L. Peeva, J. da Silva Burgal, I. Valtcheva, A.G. Livingston, Continuous purification of active pharmaceutical ingredients using multistage organic solvent nanofiltration membrane cascade, Chem. Eng. Sci. 116 (2014) 183-194.

[16] A. Caus, L. Braeken, K. Boussu, B. Van der Bruggen, The use of integrated countercurrent nanofiltration cascades for advanced separations, J. Chem. Technol. Biotechnol. 84 (2009) 391-398.

[17] V.S.K. Adi, M. Cook, L.G. Peeva, A.G. Livingston, B. Chachuat, Optimization of OSN Membrane Cascades for Separating Organic Mixtures, in: Z.K. and M. Bogataj (Ed.), Comput. Aided Chem. Eng., Elsevier, Amsterdam, Netherlands, 2016: pp. 379-384.

[18] J. F. Kim, A. Freita da Silva, I.B. Valtcheva, A.G. Livingston, When a membrane is not enough: A simplified membrane cascade using Organic Solvent Nanofiltration (OSN), Sep. Purif. Technol. 116 (2013) 277-286.

[19] A.M. Arias, M.C. Mussati, P.L.Mores, N.J. Scenna, J.A. Cabalerro, S.F. Mussati, Optimization of multi-stage membrane systems for $\mathrm{CO}_{2}$ capture from flue gas, Int. J. Greenh. Gas Control. 53 (2016) 371-390.

[20] J. Vanneste, S. De Ron, S. Vandecruys, A.A. Soare, S. Dravishmanesh, B. Van der Bruggen, Techno-economic evaluation of membrane cascades relative to simulated moving bed chromatography for the purification of mono- and- oligosaccharides, Sep. Purif. Technol. 80 (2011) 600-609.

[21] A. Lejeune, M. Rabiller-Baudry, T. Renouard, Design of membrane cascades according to the method of McCabe-Thiele: an organic solvent nanofiltration case study for olefin hydroformylation in toluene, Sep. Purif. Technol. 195 (2018) 339-357.

[22] A. Lejeune, Nanofiltration organique appliquée à l'hydroformylation des oléfines dans le toluene. Etude expérimentale, conception et simulation de cascades. (Organic solvent nanofiltration applied to olefin hydroformylation in toluene. Experimental study, design and 
simulation of cascades) PhD Thesis université de Rennes 1, France, 2017.

[23] P. Schmidt, E.L. Bednarz, P. Lutze, A. Górak, Characterisation of Organic Solvent Nanofiltration membranes in multi-component mixtures: Process design workflow for utilizing targeted solvent modifications, Chem. Eng. Sci. 115 (2014) 115-126.

[24] P. Gabrielli, M. Gazzani, M. Mazzotti, On the optimal design of membrane-based gas separation processes, J. Membr. Sci. 526 (2017) 118-130.

[25] R. Abejón, A. Garea, A. Irabien, Optimum design of reverse osmosis systems for hydrogen peroxide ultrapurification, AIChE J. 58 (2012) 3718-3730.

[26] M.S. Avgidou, S.P. Kaldis, G.P. Sakellaropoulos, Membrane cascade schemes for the separation of LPG olefins and paraffins, J. Membr. Sci. 233 (2004) 21-37.

[27] T. Renouard, A. Lejeune, M. Rabiller-Baudry, Separation of solutes with an organic solvent nanofiltration cascade: designs, simulations and systematic study of all configurations, Sep. Purif. Technol. 194 (2018) 111-122.

[28] M. Mulder, Basic Principles of Membrane Technology, 1996, 2 E, Springer, Netherlands, 1996.

[29] S. Darvishmanesh, L. Firoozpour, J. Vanneste, P. Luis, J. Degrève, B.V. der Bruggen, Performance of solvent resistant nanofiltration membranes for purification of residual solvent in the pharmaceutical industry: experiments and simulation, Green Chem. 13 (2011) 34763483 .

[30] A. Caus, S. Vanderhaegen, L. Braeken, B. Van der Bruggen, Integrated nanofiltration cascades with low salt rejection for complete removal of pesticides in drinking water production, Desalination. 241 (2009) 111-117.

[31] J. Vanneste, D. Ormerod, G. Theys, D. Van Gool, B. Van Camp, S. Darvishmanesh, B. Van der Bruggen, Towards high resolution membrane-based pharmaceutical separations, J. Chem. Technol. Biotechnol. 88 (2013) 98-108.

[32] Dow Chemicals, FILMTECH Reverse Osmosis Membranes - Technical Manual, https://dowac.custhelp.com/app/answers/detail/a id/3428/ /filmtec-membranes---filmtecstechnical-manual available online Dec. 2017.

[33] E. Harrington. The desirability function, Industrial Quality Control, 21 (1965) 494 - 498.

[34] K. Khoder, Optimisation de composants hyperfréquences par la technique des plans à surfaces de réponses (Optimization of microwave components using the surface-to-surface technique) PhD Thesis, Université de Limoges, 2011, France. 
[35] Z. He, P.F. Zhu, A note on multi-response robust parameter optimization based on RSM, Proceeding of $4^{\text {th }}$ IEEE Int. Conf. Manag. Innov. Technol. (2008) 1120-1123. 


\section{Highlights}

- Simulation of performances of membrane cascades devoted to OSN

- Graphical representation to evidence reachable performances of membrane cascades

- Graphical representation to evidence main compromises to solve facing the separation

- OSN applied to the hydroformylation of 10-undecenitrile in toluene 